\title{
The Why and How of Amino Acid Analytics in Cancer Diagnostics and Therapy
}

Friederike Manig ${ }^{1,2,5}$, Konstantin Kuhne ${ }^{3}$, Cläre von Neubeck ${ }^{1,4}$, Uwe Schwarzenbolz ${ }^{5}$, Zhanru Yu, Benedikt M. Kessler ${ }^{6}$ Jens Pietzsch ${ }^{3,5}$ and Leoni A. Kunz-Schughart ${ }^{1,2,7}$

${ }^{1}$ OncoRay - National Center for Radiation Research in Oncology, Faculty of Medicine and University Hospital Carl Gustav Carus, Technische Universität Dresden, Germany

2/3 Helmholtz-Zentrum Dresden-Rossendorf, ${ }^{2}$ Institute of Radiooncology, and ${ }^{3}$ Department of Radiopharmaceutical and Chemical Biology

${ }^{4}$ German Cancer Consortium (DKTK), partner site Dresden, and German Cancer Research Center (DKFZ), Heidelberg; Germany

${ }^{5}$ Department of Chemistry and Food Chemistry, Technische Universität Dresden, Dresden, Germany

${ }^{6}$ Target Discovery Institute, Nuffield Department of Medicine, University of Oxford, Roosevelt Drive, Oxford, OX3 7FZ, UK.

${ }^{7}$ CRUK/MRC Oxford Institute for Radiation Oncology, Old Road Campus Research Building, Roosevelt Drive, Oxford OX3 7DQ, UK.

\# Corresponding author: Prof. Dr. Leoni A. Kunz-Schughart, OncoRay - National Center for Radiation Research in Oncology, Faculty of Medicine and University Hospital Carl Gustav Carus, Technische Universität Dresden Fetscherstrasse 74, PO Box 41, 01307 Dresden Germany,

phone: +49-351-4587405, fax: +49-351-4587311, e-mail: leoni.kunz-schughart@oncoray.de

Acknowledgements: Our work related to amino acid detection and metabolic targeting has been supported by the European Social Fund (ESF) and Free State of Saxony, the Else Kröner-Fresenius Foundation and the German Academic Exchange Service (DAAD). OncoRay is funded by the BMBF in the program "Center for Innovation Competence". We thank Mrs. Melanie Hüther and Mr. Jürgen Löbner for their efforts and technical assistance as well as Mrs. Christiane Kunz B.A. for excellent design advice.

Conflict of Interest: The authors claim no conflict of interest. 


\section{Abbreviations}

AA - amino acid/amino acids; AAD - amino acid detection; ADI - arginine deiminase; ADT - arginine deprivation therapy; ALL - acute lymphoblastic leucemia; APCI - atmospheric pressure chemical ionization; APPI - atmospheric pressure photo ionization; AQC - aminoquinolyl-N-hydroxysuccinimidyl carbonate (AQC); CE - capillary electrophoresis; $\mathrm{Cl}$ - chemical ionization; dabsyl-Cl - 4-(4-dimethylaminophenylazo)benzene sulfonyl chloride; dansyl-Cl - 5-(dimethylamino)naphthalene-1-sulfonyl chloride; EFSA - European Food Safety Authority; EI electron impact ionization; ESI - electrospray ionization; $\mathrm{Fmoc}-\mathrm{Cl}$ - fluorenylmethyloxycarbonyl chloride; GBM glioblastoma multiforme; GC - gas chromatography; HCA - heterocyclic amines; HILIC - hydrophilic interaction liquid chromatography; HPLC - high performance liquid chromatography; LC-MS - liquid chromatography mass spectrometry; LLOQ - lower limit of quantification; LOD - limit of detection; MR - maillard reaction; MRM - multiple reaction monitoring; MS - mass spectrometry; MS/MTR - methionine synthase/5-methyltetrahydrofolatehomocysteine methyltransferase; MTAP - methylthioadenosine phosphorylase; OPA - o-phthalaldehyde; PET positron emission tomography; PITC - phenylisothiocyanate; PKU - phenylketonuria; RP - reversed phase; RPLC - reversed phase high performance liquid chromatography; SPE - solid phase extraction; TFA - trifluoroacetic acid; UHPLC - ultra high performance liquid chromatography; VOCs - volatile organic compounds

\section{Abstract $^{1}$}

Pathological alterations in cell functions are frequently accompanied by metabolic reprogramming including modifications in amino acid metabolism. Amino acid detection is thus integral to the diagnosis of many hereditary metabolic diseases. Metabolic diseases and their development come along with a complex dysregulation of genetic and epigentic factors affecting metabolic enzymes. Cancer cells might transiently or permanently become auxotrophic for non-essential or semi-essential amino acids such as asparagine or arginine. Also, transformed cells are often more susceptible to local shortage of essential amino acids such as methionine than normal tissues. This offers new points of attacking uniquemetabolic features in cancer cells. To better understand these processes, highly sensitive methods for amino acid detection and quantification are required. Our review summarizes the main methodologies for amino acid detection with a particular focus on applications in biomedicine and cancer, provides a historical overview of the methodological pre-requisites in amino acid analytics. We compare classical and modern approaches such as the combination of gas chromatography and liquid chromatography with mass spectrometry (GC-MS/LC-MS). The latter is increasingly applied in clinical routine. We therefore illustrate an LC-MS workflow for analyzing arginine and methionine as well as their precursors and analogs in biological material. Pitfalls during protocol development are discussed, but LC-MS emerges as a reliable and sensitive tool for the detection of amino acids in biological matrices. Quantification is challenging, but of particular interest in cancer research as targeting arginine and methionine turnover in cancer cells represent novel treatment strategies.

\footnotetext{
1 This comprehensive review aims at presenting and discussing the amino acid detection tools of interest in biomedical science and cancer research but does not claim to cover the entire field and literature, respectively. The authors apologize to those researchers whose work has not been mentioned due to restrictions in space and time.
} 
1. From Food Chemistry to Biomedicine: Why to detect AAs

1.1. Background

1.2. Linking Food Chemistry and Public Health

1.3. Amino acid-associated diseases

2. AA quantification: Increasing demand in cancer research and treatment

2.1. The challenge of tumor metabolism

2.2. Asparagine targeting: An example of clinical success in ALL

2.3. The potential of arginine deprivation therapy

2.4. Methionine uptake for cancer diagnosis and therapy

2.5. Clues from cancer metabolic profiling and conclusion

3. A historical overview: Methodological pre-requisites in AA analytics

3.1. Basics: Electrophoresis via chromatography

3.2. From liquid to gas chromatography

4. Competing or complementary: Classical and modern AAD at a glance

4.1. AAD technologies - an overview

4.2. State-of-the-art: GC-MS and LC-MS

5. In Focus: Potential and challenges of LC-MS based AAD

5.1. Sample preparation and handling

5.2. Prospects and limitations of LC-MS without derivatization

6. LC-MS for monitoring specific therapy-related AAs: An example

7. Summary and Conclusion

1. From Food Chemistry to Biomedicine: Why to detect AAs

\section{$1.1 \quad$ Background}

Amino acids (AAs) - both containing amine (-NH2) or carboxylic acid $(\mathrm{COOH})$ functional groups - were already described in the early 19th century commenced with the isolation of asparagine from Asparagus sativus (Vauquelin and Robiquet, 1806). It took another six decades to elucidate the structure of asparagine (Kolbe, 1862). Today, the presence and structure of more than $300 \mathrm{AAs}$ are known (Wu, 2009) including the 21 proteinogenic AAs (selenocysteine and the 20 canonical AAs) which are required for protein biosynthesis in living organisms (Gao et al., 2015). Free and protein/peptide-bound AAs occur ubiquitously in the 
biosphere, in microorganisms, plants and animals, and are thus an integral nutritional component in species-appropriate food. AAs are specified as essential, semi-essential or nonessential depending on their actual metabolic availability within the (human) body and the divergent necessity for exogenous supply. All AAs except glycine have an asymmetric ( $\alpha-)$ carbon with carboxylic or amino groups and are optically active; their nonpolar, polar and unloaded or loaded side chain is crucial for chemical verification and defines the $A A$ classification.

Due to the omnipresence as well as the high variability of $A A$ pattern in various matrices, $A A$ detection $(A A D)$ has become an integral part in life science. The quantification of $A A s$ is primarily based on chromatographic technologies. Attributes important for chromatographic detection are the ampholytic character of AAs leading to a zwitter ion at the individual isoelectric point (IP), as well as the exclusive presence of sulfur in methionine and cysteine, which - amongst others - defines three-dimensional protein folding via the formation of disulfide bonds (Chaimbault et al., 1999; Wu, 2009). Methods of choice for AAD are high performance liquid chromatography (HPLC), capillary electrophoresis (CE) and gas chromatography (GC) (Krumpochova et al., 2015; Otter, 2012; Poinsot et al., 2010; Rigas, 2013), all of which can nowadays be combined with mass spectrometry (MS) to increase the sensitivity of detection as will be highlighted in more detail later in this essay.

The -omics era of the $21^{\text {st }}$ century is unconceivable without sensitive and selective state-ofthe-art AA analytics, in particular with the expansion from genomics to proteomics and most recently metabolomics approaches (Arapitsas et al., 2016; Becker et al., 2012; Jehmlich et al., 2015; Possemato et al., 2011; Prabhu et al., 2014). However, the field of applications for both classical as well as modern AA detection techniques is diverse as outlined in Fig. 1. It ranges from biological disciplines including zoology (Preston, 1993; Wu et al., 2016) marine research (Bermudez et al., 2015) and anthropology (Kaal et al., 2016), where samples as diverse as sediments (Larsen et al., 2015), tissues (Wu et al., 2016) and archeological materials (age determination) are monitored, to the use in biotechnology and pharmaceutical research and industry, e.g. for quality control and drug design (Holzgrabe et al., 2010; llisz et al., 2006; Peura et al., 2013; Vlaardingerbroek et al., 2013). AAD can be performed in diverse liquid and solid matrices including geological samples, bacteria and plant masses, DNA/protein or RNA/protein extracts, blood, serum and plasma, urine and stool as well as tissue and biopsy samples. Indeed, body fluids are of particular interest in biomedicine and clinical chemistry.

\subsection{Linking Food Chemistry and Public Health}


Food chemistry is a major area of application for AAD. The AA composition of particular food products is for example analyzed to calculate a protein digestibility-corrected AA score (PDCAAS) as measure for nutritional protein quality based on the amino acid profile and the human requirements for essential AAs (Bellomaria et al., 2016; Rutherfurd et al., 2015; Sarwar, 1984; Schaafsma, 2000). At the same time, the AA composition and abundance may affect food quality and thus needs to be monitored already during production. As an example, free $A A$ and ammonium are the main nitrogen source for alcoholic fermentation by yeast. Reduced AA concentrations can lead to malfermentation whereas the excess of AAs might result in microbiological instability, both counterproductive for high quality wine production. Here, AAs as well as specific noxious derivatives, such as biogenic amines that serve as an indication for microbiological deterioration, are routinely determined via HPLC and CE (Acunha et al., 2016; Ortega-Heras et al., 2014; Wang et al., 2014). Biogenic amines are decarboxylated AAs and nitrogenous organic compounds that can act as neurotransmitters and precursors for hormones and vitamins (Karovicova and Kohajdova, 2005; Rai et al., 2013). Their accumulation in the body has been linked to several adverse health effects such as headache and allergic reactions (Binner et al., 2013; Rabie et al., 2014; Santos 1996). For this reason, the European Food Safety Authority (EFSA) has proposed a risk assessment for fermented foods based primarily on the most abundant biogenic amines histamine and tyramine (Efsa, 2011).

Another interface between AA derivatives, food chemistry and public health is the presence of Amadori compounds in various food products which serves as an indicator for the extent of heating, e.g. during milk processing via ultra-high temperature treatment and conventional sterilization (Mehta and Deeth, 2016; Wellner et al., 2009). The direct detection of these glycated AAs is in principle adapted from AAD technologies (Hellwig and Henle, 2014; Lee et al., 2015). Amadori compounds are bright and unscented products of the first step of the maillard reaction (MR) which is a complex biochemical reaction between free AAs or proteins and carbohydrates (Galli, 2007) also called "non-enzymatic browning" due to the formation of aromatic, mostly colored end stage reaction products during cooking in the absence of enzymes. Indeed, both beneficial and hazardous MR products may be formed depending on the way of food processing as emphasized in a recent review by Tamanna and Mahmood (Tamanna and Mahmood, 2015). Major issues in agriculture and food preparation are thus the enhancement and preservation of nutritional value on the one hand and the avoidance of harmful ingredients such as heterocyclic amines (HCAs) and acrylamide on the other hand. The latter is mainly produced in an amylaceous environment via biochemical modification of asparagine (Lineback et al., 2012; Yaylayan et al., 2005) and was already classified as human carcinogen (Group 2A) by the International Agency for Research on Cancer in the World Health Organization (IARC-WHO) (IARC, 1994) in 1994. Still, there are no standard regulations on 
HCAs, although roughly at the same time the IARC had appointed several different HCA species with carcinogenic potential (IARC, 1993; Lee et al., 2015; Tamanna and Mahmood, 2015).

Human condition is certainly influenced by the daily ingested AA content and composition. This becomes evident in particular in patients with diseases related to $A A$ incompatibilities and enzyme defects (van Vliet et al., 2014). Fast and reliable detection of AA misbalances in blood, plasma, serum, urine and liquor samples is thus of tremendous importance and routine in clinical chemistry. Classical clinical indications for AA analysis are neurological symptoms or dysregulations, metabolic imbalances and acidosis, gastrointestinal disorders, kidney diseases and sepsis as well as the monitoring of patients in the course of a diet (Batch et al., 2014; Fitian et al., 2014; Niewczas et al., 2014). Dietetic food with particular nutritional compositions is commercially available for selected groups of people not only for energy restriction during weight loss but in particular for infants and young children and for people with gluten intolerance or other specific medical conditions as depicted. The application of AA analytics for quality control of such special food for infants and medical purposes is directed for all EU countries via EU-Regulation No 609/2013 (effective date: 20 July 2016.)

\subsection{Amino acid-associated diseases}

The detection of AA-associated diseases is especially important in newborns. The newborn screening which is standard in many well-developed countries was established to identify apparently healthy infants with serious inherited, monogenic disorders early enough so that they can be treated by drug or dietary interventions before exhibiting clinical symptoms (Pourfarzam and Zadhoush, 2013; Summar et al., 2013; Therrell et al., 2014). Indeed, a range of inborn errors of metabolism (IEM) with high morbidity or mortality if left untreated can be identified by a single test via an abnormal AA profile in a blood spot of the neonate (Lehotay et al., 2011; Therrell et al., 2014). In most cases, the analysis is performed via liquid chromatography combined with mass spectrometry (LC-MS) (Becker et al., 2012; la Marca, 2014; Lehotay et al., 2011; Pitt, 2009; Zurawicz and Kaluzna-Czaplinska, 2015).

Each specific disorder detected via the newborn screening is rare, but their cumulative incidence accounts to 1:1,500 - 1:5,000 live births calling for a worldwide action (Pourfarzam and Zadhoush, 2013; Zhang et al., 2000). Hereditary phenylketonuria (PKU) was the first disease tested with a screening method in the 1960's and is part of the newborn screening with high relevance. PKU leads to an accumulation of phenylketons in the urine without synthesis of tyrosine; the ratio of respective AAs in the blood is indicative for diagnosis (Shushan, 2010; Staudigl et al., 2011). PKU is asymptomatic in newborn, but untreated it leads to irreversible cognitive impairment, hyperactivity, autistic-like behaviors and seizures. The therapy consists of a lifelong dietary phenylalanine restriction combined with tyrosine 
supplementation to control the disease (Al Hafid and Christodoulou, 2015; Blau et al., 2010; Therrell et al., 2014). Other AA disorders with similar health effects include urea cycle malfunctions leading to citrullinemia or argininaemia and resulting in hyperaminoacidurias (van Vliet et al., 2014). Here, the dietetic treatment comprises protein restriction and food supplementation with arginine. Despite these well-described metabolic disorders, there is increasing evidence that other developmental damage manifestations are reflected by and causally relate to AA misbalances. As an example, Evans et al (Evans et al., 2008) systematically analyzed the plasma AA profile in 34 autistic children using HPLC and GC and concluded from their data that autism may be attributed to an imbalance of neurotransmitters caused by the abnormal AA pattern in the blood. Today, the respective AA status is discussed as a biomarker profile for the early diagnosis of autism (Evans et al., 2008; Naushad et al., 2013; Zurawicz and Kaluzna-Czaplinska, 2015). In gerontology, the relevance of the AAneurotransmitter axis was in principle recognized in the context of dementia and Alzheimer's disease already in the 1980s (Degrell et al., 1989; Tarbit et al., 1980). However, it has come into focus again only recently, when specific AAs such as arginine, methionine, glutamine/glutamate and/or asparagine/aspartate were shown to be altered in the plasma, cerebrospinal fluid and/or brain tissue of patients (Gueli and Taibi, 2013) as well as in mouse and rat models of Alzheimer's disease (Kan et al., 2015; Xing et al., 2016).

$A A D$ is of course highly informative in all age groups including juveniles and young adults. While glycated hemoglobin $\mathrm{A} 1 \mathrm{c}(\mathrm{HbA} 1 \mathrm{c})$ is an approved general biomarker in patients with diabetes (Jones et al., 2014; Nathan et al., 2014), aromatic and branched chain AAs are particularly associated with insulin resistance in Type 2 diabetes (Giesbertz and Daniel, 2016; Morris et al., 2012; Stancáková et al., 2012; Wiklund et al., 2014). Indeed, several recent studies each based on cohorts of $>1,500$ individuals (up to 5,000) from different selected populations including Europe demonstrate the predictive value of these specific AAs for risk assessment in normoglycemic adults to develop diabetes, metabolic syndrome and/or cardiovascular disease (Magnusson et al., 2013; Tillin et al., 2015; Wuertz et al., 2013; Yamakado et al., 2015).

The examples given above reveal that AAs play an important role in numerous metabolic disorders. Malignancies are based on genetic alterations but may also be considered as metabolic diseases. Aerobic glycolysis (Warburg effect) and the development of spatiotemporal regions of hypoxia and tissue acidosis are the best known and well-studied phenomena in this context (Cairns et al., 2011; Jang et al., 2013) but not exclusive. Indeed, cell metabolism is reprogrammed during carcinogenesis through complex genetic and epigentic dysregulation of a variety of metabolic enzymes in glycolysis, tricarboxylic acid cycle, oxidative phosphorylation and even beyond including alterations in AA metabolism (Ghaffari et al., 2015; Li et al., 2016). This on the one hand may induce alternative crosstalk or feedback 
mechanisms and restore energetic plasticity to support tumor cell survival and proliferative activity, but on the other hand also opens a window for therapeutic intervention. The relevance of $A A$ supply and the potential for AA metabolic targeting in cancer shall thus be particularly highlighted in the next chapter as it requires state-of-the-art AAD technology.

\section{AA quantification: Increasing demand in cancer research and treatment}

\subsection{The challenge of tumor metabolism}

More than 14 million new cases of cancer and $>8$ million cancer-related deaths have been reported worldwide in 2012/2013 with an ongoing upward trend - these are the alarming numbers derived from the GLOBOCAN study directed by the WHO International Agency for Research on Cancer (IARC)(Ferlay et al., 2015) and the GBE initiative at the Institute for Health Metrics and Evaluation (IHME) at the University of Washington (Fitzmaurice et al., 2015). Malignancies are thus among the top non-communicable lethal diseases globally, and in particular in the well-developed countries with their aging population. Remarkable progress in surgical techniques, in image-guided photon and particle therapy as well as in the development of numerous therapeutic treatment options - ranging from classical and novel chemotherapeutic drugs to a broad range of individually applicable targeted therapeutics have led to a significant improvement in the clinical management of some cancer types. However, the overall cure rate has slightly increased with some malignant diseases remaining an unsolved therapeutic mystery such as pancreatic cancers and glioblastomas, thereby underlining the continuing demand for innovative strategies in diagnostics and therapy (Stewart and Wild, 2014).

Several researchers have shown that body fluids of healthy controls and breast cancer patients vary significantly in the levels of some AAs (Barnes et al., 2014; Cascino et al., 1995; Cheng et al., 2015; Poschke et al., 2013). The same was reported for lung (Cascino et al., 1995; Cobo Dols et al., 2006; Shingyoji et al., 2013; Zhao et al., 2014), ovarian (Maruyama et al., 2014), head and neck (Cobo Dols et al., 2006), gastric (Fan et al., 2012; Miyagi et al., 2011) and pancreatic (Fukutake et al., 2015; Miyagi et al., 2011) as well as colorectal cancer patients (Bener et al., 2006; Leichtle et al., 2012; Yatabe et al., 2013). These findings imply that AA profiling in plasma/serum, other body fluid or selected tissue samples might be a new tool for early diagnosis of various cancers as suggested by some authors and also summarized in (Simińska and Koba, 2016). At least, AA analysis can complement other innovative strategies for early disease detection such as the monitoring of volatile organic compounds (VOCs). Volatolomics approaches have for example been applied for the profiling of physicochemical changes in both invasive and non-invasive cancers (Le et al., 2014; Vishinkin and Haick, 2015; Broza et al., 2015) and are useful as diagnostic tools for several cancer entities, e.g. in prostate (Khalid, 2015\}, breast (Barash et al., 2015) and lung (Gasparri et al., 2016). Depending on the 
analyte(s) of interest, volatolomics can be performed by array-based biosensing techniques with recognition elements and suitable transducers (Gasparri et al., 2016; Le et al., 2014) or via GC-MS by analyzing the headspace of a sample (Barash et al., 2015; Khalid et al., 2015). However, AAs are non-volatile and cannot be directly measured by such approaches as they require derivatization as detailed in chapters 3 and 4 . Nonetheless, AA profiling might be diagnostically informative, but by itself may not be adequate for the design of novel metabolic targeting strategies. Indeed, detailed mechanistic insight into cancer-specific metabolic alterations including AA anabolism and catabolism is necessary for the design of well-directed metabolic interventions.

After decades of research to mechanistically understand the Warburg effect phenomenon and to unravel the complex face of the tumor metabolome beyond aerobic glycolysis and therapeutically-relevant hypoxia-driven adaptations (Hirschhaeuser et al., 2011; Horsman and Vaupel, 2016; Jose et al., 2011; Marchiq and Pouyssegur, 2016; Tatum et al., 2006), metabolic targeting and (anti)-metabolic therapy, respectively, are still in their infancy. One of the reasons for early disappointment and delayed progress in this field could be that a benefit for patient outcome might manifest primarily or exclusively after combined treatment, e.g. via multimetabolic targeting and/or in combination with curative approaches such as radiotherapy. Energy metabolism has gained particular attention because of the cancer cells' exorbitant energy demand due to high proliferation rates and an abnormal micromilieu (Ghaffari et al., 2015). Indeed, energy resources are not only required for lipid and macromolecule production during proliferation but also for DNA synthesis and repair (Dang, 2012; Scanlon and Glazer, 2015). However, several intermediate metabolic programs are also altered in (proliferating) tumor cells including the turnover of proteinogenic amino acids which is closely linked to the mTOR and ER stress response pathways and offers additional points of attack for metabolic targeting. A comprehensive overview on recent findings related to the regulation and crosstalk of glucose, fatty acid and amino acid metabolic pathways highlighting some relevant cancer therapy strategies is given in (Li and Zhang, 2016).

In general, cancer cells appear to very efficiently utilize all physiological exogenous sources to cover their enhanced demand for proteinogenic AAs and even the absence of non-essential AAs can disturb the delicate (abnormal) balance in tumor metabolism. Evidentially, they might transiently or permanently become auxotrophic for non-essential or semi-essential amino acids and are also often more susceptible to local shortage of essential amino acids than normal tissues. In the following paragraphs, we will therefore exemplify the rational and challenge for designing systemic dietary or enzymotherapeutic amino acid deprivation therapies on the basis of each one non-essential, one semi-essential and one essential AA (asparagine - arginine methionine; Fig. 2) (Agrawal et al., 2012; Bertino et al., 2011; Tsai et al., 2016). It is noted though, that uptake of various, even non-essential proteinogenic AAs correlates with cancer 
cell proliferation, and that reduced exogenous supply can critically affect proliferative activity, survival or tumorigenic potential of malignant cells. Amongst others, these include glutamine (Jain et al., 2012; Mullen et al., 2012) which is not only required in protein synthesis but can enter the citric acid cycle via the $\alpha$-ketoglutarate intermediate triggering aerobic glutaminolysis (Fig. 3), as well as serine which is interconnected with glycine, involved in nucleotide de novo synthesis or may undergo serinolysis to enter the glycolytic pathway playing a role in aerobic glycolysis of cancer cells (Labuschagne et al., 2014; Maddocks et al., 2013; Maddocks et al., 2016; Possemato et al., 2011). Serine is also linked to the methionine pathway by providing ATP and one-carbon units to regenerate methionine from homocysteine thereby indirectly affecting the transfer of methyl groups to DNA and RNA (Maddocks et al., 2013; Maddocks et al., 2016). These two examples indicate that different regulatory pathways contribute to the cancer cells' sensitivity to AA depletion but do not exclusively relate to stress responses commonly seen under nutrient deficiency - and in this case transmitted by an insufficient protein formation and potential misfolding.

Amino acid auxotrophy describes the phenomenon of malignant cells to develop full dependency on the exogenous supply of selected single AAs that are per se not essential for normal cells and tissues (Agrawal et al., 2012; Bach and Swaine, 1965). This is basically due to an insufficient enzyme apparatus for intracellular de novo synthesis of these AAs, in some cancers caused by genetic or epigenetic alterations. In principle, carcinomas are affected to the same degree as sarcomas, melanomas or lymphomas (Bowles et al., 2008; Kim et al., 2009; Savaraj et al., 2015; Tomlinson et al., 2015). However, the clinically most relevant example still is the dependency of acute lymphoblastic leukemia (ALL) cells on extracellular asparagine which was discovered five decades ago (Broome, 1963; Haley et al., 1961; Horowitz et al., 1968). Subsequently, systemic treatment with the asparagine-degrading enzyme asparaginase was introduced into clinical practice already in the 1970s (Dores et al., 2012; Pieters et al., 2011; Rytting et al., 2014).

\subsection{Asparagine targeting: An example of clinical success in ALL}

Today, asparagine depletion by treatment with bacterial-derived type II L-asparaginases which degrade asparagine (Fig. 2) to aspartate and ammonia is an integral component of pediatric ALL therapy and has improved survival from < 5\% to more than $80 \%$ (Schrappe et al., 2012). The enzymotherapy is also applied in the treatment of Non-Hodgkin lymphomas in combination with various other therapeutic agents (d'Amore et al., 2015; Dreyling et al., 2013; Wang et al., 2015). Of note, type II asparaginases are induced in bacteria under aerobic conditions only and have a highly specific (but not exclusive) asparagine activity while type I arginases are expressed independently of the environmental condition and similarly hydrolyze $L$-asparagine and L-glutamine (Batool et al., 2016). The main drawbacks of enzymotherapy with L- 
asparaginase are symptomatic or asymptomatic allergic (hypersensitivity) reactions which are accompanied by loss of enzyme activity.

Essential progress in biochemical and bioengineering practice in the last century allowed the production of the first PEGylated form of asparaginase, aspargase, with superior characteristics (Abuchowski et al., 1979). In general, enzyme PEGylation aims at improving pharmacokinetics and pharmacodynamics by prolonging the circulation half-life of the therapeutic enzyme in the human body and increasing its stability under physiological conditions; in addition, PEGylated enzymes might be less immunogenic (Harris and Chess, 2003; Jiang et al., 2003; Roberts et al., 2012; Zhang et al., 2014). By now, three different forms of L-asparaginase have successfully been developed into commercial drugs, i.e. naïve E.coli asparaginase, PEGasparaginase and an asparaginase derived from the bacterium Erwinia chrysanthemi (Ali et al., 2016; Avramis et al., 2007; Pieters et al., 2011). These can be given in first, second and third line therapy due to their different immunogenic profile (Tong et al., 2013). The application, proposed mode of action, side effects and limitations of these therapeutic enzymes in childhood ALL have been summarized in numerous review articles and consensus reports published over the past five years (Ali et al., 2016; Asselin and Rizzari, 2015; Batool et al., 2016; Hijiya and van der Sluis, 2016; Pieters et al., 2011; Tong et al., 2013; van der Sluis et al., 2016). The reference list provided here is not exhaustive but highly informative and includes some articles which comprehensively describe and recapitulate the various alternative sources for L-asparaginase production ranging from numerous, mainly gram-negative bacteria via fungi and yeast to algae and actinomycetes which may well become clinically relevant in the future.

The benefit of asparaginase therapy in particular for pediatric ALL patients is beyond dispute. However, striking recent observations indicate that the underlying mechanism of asparaginase sensitivity in ALL is still not fully understood. Based on an early study in a limited number of ALL patients (Haskell et al., 1969) followed mainly by cell line and animal experiments (Aslanian et al., 2001; Hutson et al., 1997; Peng et al., 2001), it was thought for a long time that asparagine auxotrophy in ALL is exclusively due to low baseline or lack of expression of the enzyme arginine synthetase (ASNS), and that resistance to asparaginase treatment relates to an adverse (up)regulation of ASNS expression and/or activity upon treatment. However, the mechanistic interrelation began to totter when Dübbers (2000) documented that ASNS activity in acute lymphoblasic (ALL) and acute myeloblastic (AML) cell preparations from patients were highly variable and did not significantly differ. Differences in ASNS activity were only seen when they considered distinct subgroups of leukemia, i.e. AML-M5 (acute monocytic leukemia) and B-lineage ALL blast cells showed lowest ASNS activities (Dübbers et al., 2000). Stams and coworkers (Stams et al., 2003) later found no correlation between ASNS expression and sensitivity to L-asparaginase in a specific subgroup of pediatric ALL which is per se known for 
its high cellular sensitivity to the treatment and better clinical outcome (Ramakers-van Woerden et al., 2000); the subgroup accounts to about $25 \%$ of all ALL and is characterized by a $(12 ; 21)$ chromosome translocation carrying a TEL/AML1 fusion gene. The observations were later confirmed in several other ALL (sub-)groups (Appel et al., 2006; Hermanova et al., 2012; Richards and Kilberg, 2006; Su et al., 2008).

Comprehensive gene expression profiles in numerous ALL cell lines and patient materials were recorded by Fine and colleagues (2005). Overall, a consistent pattern of gene expression changes in cell lines and clinical samples could be identified upon in vitro asparagine starvation. This was independent of genetic background and chromosomal translocations in the ALL models, and did not reflect response to treatment (Fine et al., 2005). Nonetheless, the data revealed an upregulation of ASNS upon enzymotherapeutic asparagine withdrawal in asparaginase-resistant but not -sensitive cell lines, whereas neither baseline ASNS expression nor its change after treatment in vitro were predictive for L-asparaginase susceptibility of clinical samples. Indeed, a response classifier gene profile defined from the cell line data including ASNS failed in the clinical sample cohort suggesting that mechanisms of resistance other than ASNS gene and protein regulation are relevant. Different hypotheses are under investigation ranging from ASNS polymorphisms associated with additional or alternative functions of the resulting protein (Akagi et al., 2009; Ben Tanfous et al., 2015; Pastorczak et al., 2014) to the adverse impact of ALL supportive, ASNS highly expressing bone marrow-derived stroma cells (Iwamoto et al., 2007). In addition, the well-known adverse effect of silent inactivation due to patient-specific immune reactions and antibody production against the enzyme or particular drug compartments such as PEG has to be considered in this context (Ali et al., 2016; Asselin and Rizzari, 2015; Pieters et al., 2011; Tong et al., 2014; van der Sluis et al., 2016). These findings are also relevant for expanding the treatment to other cancers as those listed in Fig. 4.

The direct detection of asparagine levels in patient serum for enzymotherapy monitoring seems to be straight forward but turned out to be quite delicate. In a recent consensus report related to L-asparagine treatment in pediatric ALL patients, van der Sluis (van der Sluis et al., 2016) critically discuss this option concluding that it is impractical and unreliable for clinical use due to the rapid depletion of asparagine ex vivo in presence of asparaginase in patient blood samples. Furthermore, data interpretation appeared to be difficult due to the non-standardized definition of cut-off values for complete asparagine depletion. As an alternative, the assessment of asparaginase activity in blood/plasma samples turned out as a reproducible and reliable tool for treatment evaluation in clinical routine (van der Sluis et al., 2016). This is meaningful because serum asparagine levels significantly correlated with $E$. coli-derived asparaginase serum activities in several earlier studies (Avramis et al., 2007; Douer et al., 2007; Pieters et al., 2008). Measuring of asparagine levels was thus required to approve 
asparaginase activity as readout and is still used in experimental settings where researchers can more easily comply with rapid, demanding sampling procedures. Anyways, the detection of amino acid level in pharmacodynamics and metabolic targeting studies seems more common for monitoring arginine withdrawal strategies which shall be highlighted next (Ensor et al., 2002; Izzo et al., 2004; Kelly et al., 2012; Mauldin et al., 2012; Stone et al., 2012a).

\subsection{The potential of arginine deprivation therapy}

The addiction of tumor cells to exogenous arginine was recognized already in the last century when mycoplasma contaminations afflicted many labs worldwide manifested in growth arrest in animal cell cultures. This was mainly due to the fact that some mycoplasma strains utilize enzymatically degraded arginine for energy production leading to an arginine deficiency in the contaminated cell cultures (Altucci et al., 1966; Capiaumont et al., 1995; Fenske and Kenny, 1976). Systematical depletion of arginine for cancer treatment, i.e. arginine deprivation therapy (ADT), has been developed more recently as a new promising enzymotherapeutic anti-cancer strategy which has proven anti-proliferative and/or pro-apoptotic effects in various cancer cells in vitro and in vivo (for review see (Fultang et al., 2016; Qiu et al., 2015) (Fig. 4). Besides protein biosynthesis, arginine (Fig. 2) as a nitrogen-rich semi-essential amino acid is for example vital for the production of $\mathrm{NO}$, creatine, and urea, and also contributes to intracellular proline and glutamate synthesis. Under certain physiological and pathophysiological conditions, such as growth or stress, arginine can be de novo synthesized intracellularly from ornithine (mainly in liver and kidney) or citrulline (basically in all mammalian cell types) via selected steps and enzymes of the urea cycle as illustrated in Fig. 3 (Morris, 2006; Shambaugh, 1977). The citrulline level in human plasma is lower than arginine by about a factor of two and may not be sufficient for complete compensation. However, citrulline availability is most probably not limited due to a constant uptake from the gut as well as production in the mitochondria of enterocytes from glutamine and proline via the three key regulatory enzymes Pyrroline-5-carboxylate synthase, $\mathrm{N}$-acetylglutamate synthase, and proline oxidase. The regulatory processes determining the citrulline resources via the gut are quite complex, but high arginine levels in the blood were shown to reduce this channel of supply (Breuillard et al., 2015; Curis et al., 2007; van de Poll et al., 2007; Fujita and Yanaga, 2007; Wu, 2009).

The enzymes converting arginine from ornithine and/or citrulline are expressed in a cell type, functional and differentiation-associated manner (Husson et al., 2003). Their absence or downregulation can cause auxotrophy for arginine. Reduction or lack of ornithine transcarbamylase (OTC), which is primarily expressed in normal hepatocytes, is frequently seen in auxotrophic hepatocellular carcinomas (Feun et al., 2008; Sugimura et al., 1992). In other organs, modifications in argininosuccinate synthetase (ASS-1) rather than argininosuccinate lyase (ASL) seem to play a major role in the development of cancer cell 
auxotrophy such as melanoma, small cell lung cancer, pancreatic cancers and others (Delage et al., 2012; Dillon et al., 2004; Hu and Cheung, 2009; Khoury et al., 2015; Qiu et al., 2014).

Several studies imply that the expression of ASS-1 is epigenetically down-regulated in arginine auxotrophic tumors via methylation of the ASS-1 promoter in the $\mathrm{CpG}$ island region (Delage et al., 2012; Dillon et al., 2004). In normal cells, lack of arginine leads to cell cycle arrest - if cells were not yet in $\mathrm{G}_{0}$ phase and/or differentiated, and, most importantly, ASS protein levels increase to enhance the citrulline-to-arginine conversion for survival and maintenance of cellular AA homeostasis. Cancer cells may not only have lost this regulatory mechanism, but they also seem to be highly susceptible to arginine deficiency because of their abnormal cell cycle regulation. The latter is supported by the strong combinatorial effects of ADT demonstrated even in some ASS-positive malignant cells (Bobak et al., 2016; VynnytskaMyronovska et al., 2013; Vynnytska-Myronovska et al., 2016; Kurlichshuk, 2016). In the absence of arginine, cancer cells also stop growing. However, subsequent cell cycle arrest might be poorly controlled so that some of them cannot maintain homeostasis, undergo autophagy and/or directly activate signaling pathways to apoptosis similar to the responses seen in cancer cells lacking ASS (Bobak et al., 2016; Delage et al., 2012; Gong et al., 2000; Pardee, 1974; Quu et al., 2015; Shuvayeva et al., 2014).

The reduction of blood and tissue as well as cell culture arginine level can be achieved by enzymotherapy. While cell culture studies can also be performed with arginine-free media compositions, arginine-free diets are insufficient for critically reducing arginine-levels in the body. There are mainly two enzymes that can be applied for this purpose: arginine deiminase (ADI), e.g. from Mycoplasma arginini, which hydrolyses arginine into citrulline and ammonia, and recombinant arginase which degrades arginine to ornithine and urea. The xenobiotic ADI shows pharmacodynamics advantages which made it beforehand more attractive to clinicians and is thus better investigated (Patil et al., 2016). The enzymes are usually PEGylated for in vivo use (Bobak et al., 2016; Miyazaki et al., 1990; Savaraj et al., 2010). ADI is suitable for ASS negative tumors due to the conversion into citrulline which could reduce efficacy in ASS positive cells; ASS expression was therefore suggested as biomarker for ADI sensitivity (Han et al., 2016; Kelly et al., 2012). Today, PEGylated ADI is commercially available and applied in several clinical phase I/II and III studies for patients with advanced hepatocellular carcinoma (NCT 01287585), small cell lung cancer (NCT 01266018) and breast cancer (NCT 01948843). It is also tested in combination with chemotherapeutics such as Gemcitabine and Paclitaxel for the treatment of patients with pancreatic carcinoma (NCT 02101580).

Arginase as an enzyme of the urea cycle is less immunogenic and exists in two isoforms: Arginase I is expressed in the liver while arginase II can be found in the mitochondrial matrix of roughly all extrahepatic cells, in particular in the kidney (extensively reviewed by Sidney $M$. Morris jr. and colleagues (Morris, 2002; Morris 2006; Morris, 2009; Wu and Morris 1998)). A 
PEGylated recombinant arginase I is preferentially used for enzymotherapy. The enzyme was improved during the past decade by modern biochemical engineering approaches. Indeed, its affinity to arginine as well as the rather moderate catalytic activity under physiologic conditions could be essentially enhanced by replacing $\mathrm{Mn}^{2+}$ with $\mathrm{Co}^{2+}$ in the active center (Stone et al., 2012a; Stone et al., 2010). Recombinant arginase I is now also in clinical trials for hepatocellular carcinoma (NCT 00988195), renal cell carcinoma, melanoma and prostate adenocarcinoma (NCT 02285101), as well as in a combinatorial setting with chemotherapeutics, i.e. oxaliplatin and capecitabine (NCT 02089633). Detailed information about therapeutic arginine-depleting enzymes is given in (Patil et al., 2016).

The development of resistance to ADT appears to be a serious problem and is suggested to mainly relate to an increase in ASS-1 expression upon treatment in initially ASS-1 deficient cancers. This is supported by systematic studies in ADT sensitive melanoma cells and their ADT-resistant counterparts developed via ADI exposure (ADI'variants) (Long et al., 2013; Tsai et al., 2009). Here, the ADIr variants showed enhanced ASS-1 expression which correlated with an increased c-myc transcription factor binding to the ASS-1 promotor. Resistance was also accompanied by an essential metabolic reprogramming manifested in enhanced AKT and reduced mTOR signaling. Also, alterations in glycolytic and glutaminolytic pathways (transporters and/or metabolic enzymes) were reported which more or less all seemed to be controlled via c-myc activity while HIF-1 $\alpha$ was proposed as a negative regulator in this scenario (reviewed in Feun et al., 2015; Kuo et al., 2010). Amongst others, metabolic reprogramming rendered the cells more susceptible to glutamine inhibitors, indicating that multi-metabolic combinatorial targeting might be a more efficient innovative therapeutic strategy for these cancers. Such treatment options are of particular interest since the antitumor activity of arginine deprivation monotherapy in animal models and clinical trials seems lower as expected from in vitro data. This might be due to the putative support of ASS-deficient cancer cells by surrounding ASS-positive stromal cell compartments, but may also result from the lack of reflection of the in vivo situation in the majority of the in vitro assays applied earlier. Indeed, cancer cells in three-dimensional (3-D) spheroid culture were found to be less susceptible to single amino acid deprivation than the same cells grown in monolayer culture. Also, utilization of citrulline as arginine precursor in the 3-D assay seemed to better reflect the in vivo situation (Vynnytska-Myronovska et al., 2012; Vynnytska-Myronovska et al., 2013). By using such 3-D assays, we recently proposed the combination of ADT with the arginine analog canavanine plus irradiation as a new treatment strategy resulting in massive radiosensitization of cancer cells, apoptotic cell death and/or ER stress responses (Bobak et al., 2016; VynnytskaMyronovska et al. 2012; Vynnytska-Myronovska et al., 2013; Vynnytska-Myronovska et al., 2016; Kurlichshuk, 2016). 
Successful and efficient depletion of arginine in the blood by the proposed enzymotherapeutical approach (ADI or arginase) is critical for treatment outcome. Monitoring of arginine levels in plasma samples of animals and patients has thus been an integral part of several in vivo studies (Ensor et al., 2002; Izzo et al., 2004; Kelly et al., 2012; Mauldin et al., 2012; Stone et al., 2012a) although no standardized routine protocol is proposed yet. The particular challenge as well as an easy handling procedure for identifying and quantifying arginine, its precursors and analogs in biological matrices is therefore highlighted in chapter 6 .

\subsection{Methionine uptake for cancer diagnosis and therapy}

The enhanced dependency of cancer cells on exogenous methionine (Fig. 2) was initially described in 1959 for subcutaneously transplanted Walker carcinosarcoma xenografts in Sprague-Dawley rats fed over a period of 5 days with specific AA-supplemented or -deprived forage solutions (Sugimura et al., 1959). This was later confirmed by Halpern and colleagues in a first systematic in vitro study demonstrating impaired growth of human monocytic leukemia cells, rat carcinosarcoma cells and mouse lymphatic leukemia cells when medium was methionine-deprived but supplemented with the methionine precursor homocysteine (Halpern et al., 1974). A particularly high demand for methionine was in the following reported for cancer cells of different origins including human lung adenocarcinoma and acute lymphoblastic leukemia (Kreis and Goodenow, 1978), W-256 rat breast carcinoma cells (Hoffman et al., 1978), rat sarcoma and murine leukemia cells (Koziorowska et al., 1980) and others. Soon thereafter, it was discovered that not all human tumor cells depend on methionine supply with two studies in a panel of human tumors reporting relative methionine-independence for 12/23 and 17/17 cases, respectively (Judde and Frost, 1988; Mecham et al., 1983).

Despite extensive research, the underlying mechanism for both, loss of dependence and enhanced demand for methionine, are still in debate. The latter is to some extend caused by the high methionine uptake in actively proliferating cells. In addition, several metabolic deficiencies have been proposed. These include (i) defects or reduced activities of the enzyme MS/MTR (methionine synthase / 5-methyltetrahydrofolate-homocysteine methyltransferase) and its co-factor vitamin B12 which catalyze the synthesis from homocysteine to methionine and modulate the folate cycle, (ii) enhanced methionine transporter activity, and (iii) last but not least defects in the methionine salvage pathway - especially loss of MTAP (methylthioadenosine phosphorylase), (Fig. 3) (reviewed in (Cavuoto and Fenech, 2012; Cellarier et al., 2003)). The elevated uptake of methionine in tumors was used to develop $\left[{ }^{11} \mathrm{C}\right]-$ methionine (MET) tracers for positron emission tomography (PET), namely [S-methyl-11 C]methionine (Comar et al., 1976) and $\left[1-{ }^{11} \mathrm{C}\right]-$ methionine (Bolster et al., 1986). These are now in clinical routine for diagnostics of brain cancers as a superior alternative to 2-deoxy-2-[18 $\mathrm{F}]$ fluoro-D-glucose which has limited value in brain due to the high basic glycolytic flux in this 
organ resulting in an unfavorable normal tissue background (reviewed in (Glaudemans et al., 2013)). Several clinical studies are ongoing to also verify the proposed prognostic value of $\left[{ }^{11} \mathrm{C}\right]$-methionine-PET imaging for the prediction of progression-free survival in primary brain tumors (Yoo et al., 2015) and recurrent malignant gliomas (Jung et al., 2016) including our own clinical trial which is aimed at early detection of recurrence (NCT01873469).

Methionine-restricted diets were tested as therapeutic strategy in combination with chemotherapy in clinical phase I studies with metastatic cancer (Epner et al., 2002), metastatic melanoma and recurrent glioma (Durando et al., 2008; Thivat et al., 2009) and metastatic colorectal cancer (Durando et al., 2010). The interventions were generally well tolerated by the patients and could lead to partial response or stable disease but larger study cohorts are missing. It was shown that methionine deprivation leads to $>90 \%$ depletion of SAM and MTA as well as a modest depletion of SAH (Tang et al., 2015). Also, epigenetic changes due to the missing main methyl-group donor under dietary conditions were identified and linked to methionine-specific gene expression (Tang et al., 2015). Dietary methionine withdrawal is also reinforced due to the finding that increased uptake of methionine in GBM was shown to alter the SAM/SAH ratio which in turn critically modified the DNA, RNA and protein methylation pattern towards a more aggressive epigenetic profile (Palanichamy et al., 2016).

A new therapeutic approach to reduce methionine represents methioninase which showed efficacy against various cancers in mouse models and was tested in macaque monkeys and in a pilot phase I trial presumably leading to best results in sequential combination therapy (reviewed in (Hoffman, 2015)). The original enzyme methionine- $\gamma$-lyase derived from Pseudomonas putida degraded methionine but was as other bacterial methioninases instable in serum and highly immunogenic. Amongst others, a recombinant cystathionine- $\gamma$-lyase with specific methionine-degrading activity was engineered and PEGylated more recently which efficiently reduced serum methionine in mice from $>100 \mu \mathrm{M}$ to $<5 \mu \mathrm{M}$ and was much less immunogenic (Stone et al., 2012b). Monitoring plasma methionine in a time-dependent manner is critical not only to guarantee sufficient, therapeutically relevant reduction of physiological methionine during diet (Durando et al., 2010; Epner et al., 2002; Thivat et al., 2009) but also to ensure that this essential amino acid does not drop below a health-threatening threshold. The latter is particularly relevant when considering delicate enzymotherapeutic treatment approaches because methionine in contrast to asparagine and arginine is not sufficiently de novo synthesized in normal cells, i.e. even transiently undetectable or low methionine levels could lead to severe side effects (Durando et al., 2010; Thivat et al., 2009) (physiological AA concentrations see Fig. 2).

Metabolomics approaches were frequently applied to study the behavior of bacteria and yeast under nutrient-deficient conditions. However, similar investigations focusing on cancer versus 
normal (human) cells are still rare. Steady-state analysis of the tumor metabolome revealed a general higher need for amino acids in several entities (Hirayama et al., 2009; Kami et al., 2013). Proteinogenic AAs as well as some important metabolites were analyzed via liquid chromatography mass spectrometry (LC-MS) in an in vitro study of ovarian OVCAR-8 tumor cells depleted for asparagine by exposure to L-asparaginase. (Purwaha et al., 2014) (see also chapter 3 ). The authors revealed that asparagine was degraded by L-asparaginase extra- and intracellularly within seconds while the intracellular concentration of all other measured $A A$, increased immediately after the onset of treatment. Accordingly, the mechanism of these cancer cells to adapt to the asparagine-deprived environment seems complex, and interconnections between different metabolic pathways may thus affect treatment outcome (Figure 3). LC/MS-based metabolomics was also recently applied for comparative metabolic profiling in primary and established glioblastoma cells, glioblastoma tissues, and normal astrocytes (Palanichamy, 2016). Here, methionine, tryptophan, 5-methylthioadenosine (MTAP) and kynurenin turned out to be differentially regulated in glioblastoma cells as compared to normal human astrocytes. Methionine was found indispensible for tumor cell growth and survival. Furthermore, the increased methionine consumption altered the SAM:SAH (S-adenosyl-L-methionine:S-adenosyl-L-homocysteine) ratio which reflects the methylation potential of the cells as SAM donates methyl groups to DNA, RNA and proteins. In another comprehensive study, Tang and coworkers (2015) monitored changes in RNA expression of MCF-7 breast cancer and PC3 prostate cancer cells upon withdrawal of different, selected single amino acids. They could show that most amino acids with the exception of glycine triggered a common transcriptional response that included specific ER stress response and cell cycle regulating genes. Beside heterogeneity, methionine deprivation resulted in particularly strong transcriptional effects which depended on the biosynthesis of creatine. The latter reduced SAM level under methionine-deprived conditions and lowered the histone methylations. This effect was abrogated upon simultaneous depletion of arginine or glycine (sources of creatine biosynthesis) indicating that the deprivation of multiple amino acids may not be superior to single amino acid withdrawal, and that combinatorial anti-cancer treatment strategies based on enzymotherapeutic and dietary amino-acid reduction have to be carefully validated in pre-clinical settings. Altogether, the authors describe a delicate crosstalk between methionine, arginine and glycine via the correspondent creatine biosynthetic pathway (Tang, 2015) (Figure 3).

In summary, different promising AA deprivation strategies are subject in preclinical and clinical cancer research and treatment. For clinical application of AA deprivation in patients, monitoring of plasma AA concentrations before and during dietary or enzymotherapeutic AA depletion should either be an inherent component for the evaluation of treatment success or alternative readouts relating to the level of $A A$ deprivation have to be identified and validated. Towards 
this end, the method of choice should be a fast and reliable routine procedure with high sample throughput and sufficient sensitivity as well as specificity. It should be inexpensive and automatable with a simple sample preparation procedure. Choosing the appropriate technology for this purpose requires a close examination of the various classical and modern analytical tools for AA quantification on the market with their potential, advantages, problems and limitations as depicted in the following chapters.

\section{A historical overview: Methodological pre-requisites in AA analytics}

\subsection{Basics: Electrophoresis via chromatography}

AA analysis is always performed in two steps - chromatographic or electrophoretic separation of the single AA from complex matrices such as biological fluids or protein hydrolysates followed by detection. For both processes, the most representative methods will be presented with a short historical overview.

Electrophoretic separation of differently charged AAs along an electric field is an integral method in molecular biology and shall thus be briefly outlined. The technologies' track record in AAD started in the late 1940s when the methodology initially developed by Arne Tiselius (Tiselius, 1937) was successfully applied in preparative AA fractionation (Butler and Stephen, 1948). Classical electrophoresis using carrier materials such as paper or gel preparations, where the AAs are visualized via ninhydrin or other stainings, can be utilized but is less sensitive than other $A A D$ technologies and is in principle more common for the separation and semi-quantitation of proteins. Capillary electrophoresis (CE) became popular particularly after the pivotal work of Verheggen, Mikkers and Everaerts (Verheggen et al., 1977) and was further developed for standardized AA and peptide analytics shortly after (Jorgenson and Lukacs, 1981). In CE, the derivatization process necessary for detection can run before, during or after separation with an in-capillary setting being preferential for handling (Tian et al., 2014). CE is a quite attractive tool for specific applications due to low costs, short separation times and easy sample management, and was therefore suggested as an alternative for the newborn screening (Jeong et al., 2013). These and other advances in CE for AAD as well as its coupling to MS have been highlighted in two recent reviews (Perez-Miguez et al., 2016; Poinsot et al., 2010). However, since CE has a relatively poor injection precision with limited repeatability, and artefacts due to frequent sample-matrix interactions, our essay will further focus on chromatographic methods for AA separation.

Chromatography as a laboratory method for $A A D$ is irretrievably linked to the pioneering work of both the American chemist and geologist David T. Day and the Russian botanist Mikhail Tswett at the beginning of the last century. Day's (1859-1925) special interest as a geologist was the study and survey of oil shale deposits. He proposed that the varying composition of mineral oils from different deposits, while originating from a common source of organic material, 
depended on fractional filtration by surrounding minerals (Day, 1897). Arguing that the geological process could be reproduced in the laboratory, he tested this hypothesis by passing oil through fuller's earth (aluminum silicate), achieving separation into fractions of light petroleum, heavier oils, and petroleum jelly (Day, 1903). Beyond the industrial application of his discovery, he was also aware of its analytical power and stated that it would be possible "to characterize oil by the correct percentage of components hydrocarbons [...]." In contrast to Day, Mikhail Tswett (1872-1919) was concerned with the analysis of biological samples, namely chloroplast pigments. In order to simplify pigment extraction procedures, Tswett evaporated leaf extracts over paper strips by adding solvents and monitored the behavior of the adsorbed pigments (Tswett, 1906a). Discoloration was dependent on the solvent, with ether only solvating carotene while alcohols led to the total elimination of pigments from the paper. He later changed the absorption material from paper to inorganic compounds with a preference on calcium carbonate $\left(\mathrm{CaCO}_{3}\right)$. Thereby, he observed a certain adsorption sequence depending on the individual pattern of substance displacement. "When a petroleum ether solution is filtered through a column of adsorbent [...], the pigments are resolved, according to the adsorption sequence, from top to bottom into various colored zones, since the more strongly adsorbed pigments displace the more weakly adsorbed ones [...]." Tswett named the method differential adsorption chromatography (Tswett, 1906a) and described a laboratory process based on his discovery (Tswett, 1906a, b) which is still in use in almost every chemical laboratory around the world. Tswett continued to publish numerous papers in the field, most of them in Russian and thus inaccessible to a broader scientific community which resulted in a 25-year latency period before the technology was internationally recognized.

The next notable progress in chromatography was documented in 1931 when Richard Kuhn, Edgar Lederer and Alfred Winterstein described the separation of isomeric compounds of carotene and xanthophylls (Kuhn and Lederer, 1931; Kuhn et al., 1931). Tswett's basic methodology was further improved by the development of both silica partition chromatography (Gordon et al., 1943; Martin and Synge, 1941) and paper partition chromatography (Consden et al., 1944), which combined a solid carrier with two liquid phases, i.e. water and an organic solvent. This facilitated the separation of structurally similar compounds, making complex biological samples amenable to analysis. Amongst others, Martin introduced the concept of theoretical plates (Martin and Synge, 1941), while Consden defined the symbol $\mathrm{R}_{\mathrm{f}}$ (retardation factor) to denominate the movement of an analyte relative to the liquid front (Consden et al., 1944). Based on these fundamentals, detection and separation techniques for increasingly complex matrices were developed; the most typical ones are delineated below.

A simple and cheap approach is thin layer chromatography (TLC) which was established for AAs in 1959 (Mutschler and Rochelmeyer, 1959). Here, AAs are separated on a membrane consisting of resin material; the detection needs a chromophore or coupling to MS (Abu-Rabie 
and Spooner, 2009). The technique is easy in handling but suffers from quantification inaccuracies and is thus utilized only in qualitative or semi-quantitative analyses these days, in particular for enantioselectivity. An overview on recent applications as well as a comparison to HPLC and GC is given in (Dolowy and Pyka, 2014; Tanwar and Bhushan, 2015).

\subsection{From liquid to gas chromatography}

In liquid chromatography, three major separation techniques must be mentioned with respect to AAD: (i) ion chromatography (IC), (ii) reversed-phase (RP) and (iii) hydrophilic interaction chromatography (HILIC), usually performed as HPLC with a higher separation efficiency. IC is the traditional method in AA analysis based on the separation of polar analytes by their varying affinity to a stationary ion exchanger (Mansour et al., 2013; Williams, 1986). While ion exchange as phenomenon was already described in the mid-19 $9^{\text {th }}$ century (Way, 1850, 1852), and synthesis of the first ion exchange resins was published in 1935 by Adams and Holmes (Adams, 1935), it was not until the work by Small, Stevens and Baumann in 1975 (Small et al., 1975 ) that IC gained real foothold in analytical chemistry. The authors described for the first time the use of sub-micrometer particles in IC and directly coupled the separation to a conductivity cell as detector, thereby reducing column size and analysis time. Another important step in the analysis of organic compounds by IC was the development of a pulsed amperometric detector in 1983, which finally allowed the detection of AAs and carbohydrates (Rocklin and Pohl, 1983). The basics of contemporary RP chromatography were described in 1950 by Howard and Martin as a development of partition chromatography (Howard and Martin, 1950). Here, silica gel was modified by dichlorodimethylsilane to enhance the interaction of hydrophobic compounds with the solid phase. The combination with a non-polar mobile phase of acetone-paraffin allowed the first separation of long-chain fatty acids. The esterification of silica with various hydrophobic groups was patented shortly thereafter (Iler, 1953), enabling the synthesis of column material with highly selected separation properties. The term hydrophilic interaction liquid chromatography was first used in a review by Alpert in 1990 to describe the combination of ion exchange resins and RP solvents (Alpert, 1990). In contrast to RP, the solid phase is modified with polar groups like amino, amide, cyano or hydroxyl functionalities, and the gradients start with a high percentage of organic modifier (Guo, 2015; Tang et al., 2014). Elution is achieved gradually by increasing the water content of the solvent. Therefore, HILIC is orthogonal to RP-LC showing higher separation efficiency for polar analytes. Since HILIC and RP can use the same solvent system, the deployment of both systems in a two-dimensional (2-D) method is feasible (Stoll et al., 2008). The term Amino Acid Analysis ( $A A A$ ) has been assigned to an AAD process based on an automated cationexchange chromatography (specific HPLC) with ninhydrin postcolumn derivatization which is used since the 1960s and comprehensively described in (Inglis, 1964; Kaspar et al., 2009a; Kellner et al., 1994; Starbuck and Busch, 1962). 
As an alternative, analysis of AAs can be performed by high resolution capillary GC (syn. gasliquid chromatography (GLC)). GC/GLC per se is highly efficient, has good sensitivity and is characterized by particularly high speed and flexibility with respect to the deployed capillary. Furthermore, the instrumentation costs are moderate. The main limitation of the approach is the need for derivatization which usually involves laborious and time-consuming procedures resulting in a loss of the GC advantage for high speed. GC was initially applied to the analysis of gases and vapors. The work of Martin \& Synge (1941) and James \& Martin (1952) and (James et al., 1952) then launched GC as a highly versatile technology applicable to a plethora of gaseous samples, liquid solutions and volatile solids; for non-volatile samples of interest, techniques such as pyrolysis GC or derivatization GC were established. Pyrolysis GC is an approach based on the thermo-chemical cleavage of non-volatile probes prior to their entry into the column/ capillary where the smaller, more volatile decomposition products are separated (Irwin and Slack, 1978). Ulehla was the first to study the pyrolysis of potassium salts of 19 AAs with 13 of them giving appropriate pyrograms for analysis (Ulehla, 1960). Further attempts at identifying the pyrolysis fragments from AA monomers were made by Kanomata \& Mashiko (1966) and by Winter \& Albro (1964). A logical extension of this technique was the early interfacing of pyrolysis GC with mass spectrometry (MS) for better identification of the decomposition products (Voellmin et al., 1966). Based on the pioneering work of Golay (1957) and Holmes \& Morell (1957), GC-MS finally proved to be one of the most sophisticated and powerful analytical tools also for AAD. However, derivatization GC became more important for GC-MS as sensitivity, specificity and efficiency of AA analysis could be tremendously improved. In order to make AAs amenable to GC separation, they have to be quantitatively converted into less polar and, essentially, volatile derivatives. The most common derivatization protocols comprise the formation of perfluoroacyl alkyl esters (Gehrke et al., 1968; MacKenzie and Tenaschu, 1974) or silylation reactions replacing active hydrogens by alkyl silyl groups (Chaves Das Neves, 1982; Gehrke et al., 1969). However, their methodological limitations include high reagent costs, laborious pre-analytical and synthetic processes requiring reagent removal and solvent exchange as well as the sensitivity of reagents and derivatives to moisture. Indirect alkylation of AAs in aqueous solutions via alkyl chloroformates in the presence of an alcohol and pyridine or 3-picoline as catalyst was introduced by Hušek and co-workers in the 1990s (Huang et al., 1993; Hušek, 1991) and turned out to be a very powerful approach. Here, the AA react in an incredibly rapid single-step procedure allowing for simultaneous acylation of the amino group and esterification at the carboxyl function at room temperature (Hušek, 1998). The derivatives can be easily extracted with an organic solvent, and an aliquot is then directly injected into the GC-MS system. The approach can be individually tailored to specific analytical aims, e.g. the analysis of specific biological/ physiological specimen (Kaspar et al., 2008; Zahradnickova et al., 2007), analysis of sulphur-containing AAs (Pietzsch et al., 1997a), 
analysis of non-protein/modified AAs (Hušek et al., 2008; Pietzsch et al., 2004), stable isotope ratio analysis of AAs (Pietzsch et al., 1997b) or chiral speciation of AAs (Simek et al., 2012). This is achieved by using different alkyl or fluoroalkyl chloroformates, e.g. methyl, ethyl, propyl, or pentafluoropropyl chloroformates, and various alcohols such as ethanol, propanol or trifluoroethanol which determine the formed esters. For MS, standard electron impact ionization (EI) can be used which is easier to maintain than chemical ionization (Cao and Moini, 1995; Pietzsch et al., 1995); ionization strategies will be further discussed in Chapter 4. Moreover, alkyl/ fluoroalkyl chloroformate derivatization of AAs can be adopted for liquid chromatography (LC) (Hušek et al., 2016). On the other hand, this approach with its variations related to the employed chloroformate and alcohol is characterized by an excellent sensitivity with a detection and quantification threshold in the low micromolar range as well as broad analytical/ calibration ranges (Kaspar et al., 2009a; Pietzsch and Pixa, 1998).

One of the limitations of this analytical technique is the challenge to analyze arginine as the guanidine moiety is unstable. The analysis of arginine and chemically related molecules by GC-MS constitutes a more general problem as reviewed recently in a highly informative article by Martens-Lobenhoffer \& Bode-Böger (2014). Indeed, two major prerequisites, vaporability and thermal stability of the derivatives, are often not given or achieved for all analytes of interest. Preparative solutions were described only for selected molecules or matrices, e.g., for dimethylarginines (Tsikas et al., 2011; Tsikas et al., 2003) or for arginine plus ornithine (Yoon, 2013), but Martens-Lobenhoffer and Bode-Böger clearly illustrate that LC-MS-based analysis of arginine and its related substances still remains the 'gold standard' (see Chapter $6)$.

\section{Competing or complementary: Classical and modern AAD at a Glance}

\subsection{AAD technologies - an overview}

HPLC is probably still the most widely used analytical method for AAD. Here, the detection of separated AAs based on ultraviolet (UV) or fluorescence (FL) light excitation has been standard for many years. Notably, peptides and proteins exhibit strong UV absorption in the range of $190-230 \mathrm{~nm}$ due to their numerous amide bonds (Goldfarb et al., 1951), but absorbance of single AAs is limited to the aromatic AAs phenylalanine, tryptophan and tyrosine which are typically detected at $280 \mathrm{~nm}$. The only AA showing real strong intrinsic fluorescence upon excitation is tryptophan which emits in the range of 335-380 nm with high intensity (Eaton, 1988). UV/FL-based identification of the other AAs requires the introduction of a chromophore into the $A A$ molecules. Historically, ninhydrin and phenyl isothiocyanate (PITC) have been among the most famous AA-derivatization reagents (Rutherfurd et al., 2009). 
First described by Ruhemann in 1910, ninhydrin as AA-reactive compound is forming a purple color (Ruhemann's purple) after reaction with primary amines or a yellow complex when reacting with secondary amines (Ruhemann, 1910a, b). Amongst others, the ninhydrin approach was used in the fundamental study by Consden, Gordon \& Martin (Consden et al., 1944 ) referenced earlier in this review as well as in the first AA analyzer described by Moore \& Stein in 1954 (Moore and Stein, 1948; Stein and Moore, 1948). After derivatization, AAs with primary amine reactions are visualized at $570 \mathrm{~nm}$, while those with secondary amines like proline and hydroxyproline can be detected at $440 \mathrm{~nm}$ (Friedman, 1974; Troll and Cannan, 1953; Yemm and Cocking, 1955). Besides its use as post-column derivatization agent in chromatographic AA analysis, ninhydrin is employed as fingerprint marker in forensic science (Odn and von Hofsten, 1954) and as an important control reagent in solid phase peptide synthesis (Kaiser et al., 1970). Another option of AA derivatization is the use of isothiocyanates (Santa, 2010). Best known is perhaps PITC - also called Edman's reagent because it is most commonly associated with the hydrolytic sequencing of peptides by Edman degradation (Edman, 1950). While yielding chemically very stable derivatives, the main drawback of PITC is its lack of fluorescence emission, leading to relatively high detection limits. For a detailed discussion on PITC-derivatization of AAs see (Sherwood et al., 1990). Today, the most popular compound for FL-detection of AAs is o-phthalaldehyde (OPA) (Klein and Linser, 1932; Zimmermann, 1930; Zuman, 2004). Derivatization is performed at basic $\mathrm{pH}$ (8-11) with organosulfur compounds like ethanedithiol (Carducci et al., 1999), 2-mercaptoethanol (Chen et al., 1997) or 3-mercaptopropionic acid (Terrlink et al., 1994). While achieving excellent sensitivity with picomolar Limit(s) of Detection (LOD), derivatization with OPA yields instable products which degrade into non-fluorescent compounds, making the analysis of complex biological matrices difficult (Garcia Alvarez-Coque et al., 1989). The repertoire of AA derivatization reagents has been broadened over the years as exemplified in Tab. 1; all of these compounds are able to form AA derivatives that allow detection in the picomolar range.

The most exciting technological progress of the past decades in AAD is clearly associated with mass spectrometry (MS). During MS analysis, ions are formed at the MS interface and transferred into a gas phase. For the determination of target molecules, ions become accelerated in an electric field, are transmitted to the analyzer and finally sorted by their $\mathrm{m} / \mathrm{z}$ (mass-to-charge) ratio. Analytes can deliberately be fragmented during this procedure depending on the type of MS. Historically, the development of GC for separation and detection by MS went hand-in-hand (see Chapter 3) (Biemann and Vetter, 1960). After the initial publications on GC in 1952 (James and Martin, 1952; James et al., 1952), the first successful application of analytical MS was already documented in 1956 by Drew who described the separation and subsequent analysis of hexane, propyne (methylacetylene), propylene and allene isomers (Drew et al., 1956). State-of-the-art GC-MS is mainly based on either electron 
ionization $(\mathrm{El})$ or chemical ionization $(\mathrm{Cl})$. Ionization by electron bombardment was first described by Dempster in 1918 for the analysis of cathode rays and determination of isotopes (Dempster, 1918; Dempster 1921). The same fundamental technique is still applied in GC-MS, with a hot filament serving as electron source and allowing the coupling of GC and EI with time of flight measurements (Gohlke, 1959). The direct ionization by electron bombardment in El constitutes a 'hard' ionization method leading to strong fragmentation of the analyte. Hence, 'softer' methods that keep the analyte molecule intact have been of great interest for the analysis of biological samples. In 1966, Munson \& Field described the use of methane as a reaction gas in the ionization process and defined the process as chemical ionization (Munson and Field, 1966). Operationally, the reaction gas is ionized first and the secondary species of ionized gas then leads to the ionization of analyte by proton or hydride transfer. In this case, electron impact on the analyte molecules is negligible due to the high excess of reaction gas, and fragmentation patterns are mostly limited to reactive centers (Arsenault et al., 1970).

\subsection{State-of-the-art: GC-MS and LC-MS}

The developmental progress towards widely applicable LC-MS has clearly been more complex. The shift in paradigms initiated by the increasing availability of commercial LC-MS systems shall be illustrated by two quotes from publications in Electrophoresis. In the ongoing series on capillary electrophoresis: Poinsot claimed in 2003 "In fact it [MS] is not often used because $M S$ is expensive, and, because of the low-molecular-mass of AAs, the detection is not sensitive." (Poinsot et al., 2003); thirteen years later, it was stated in the same series, "Thanks to its relevant advantages, providing both universality and selectivity, high sensitivity, and rich information content, MS is the most powerful detection system for CE, CEC and other separation techniques.” (Kašička, 2016). Initial problems with the coupling of LC procedures with MS primarily occurred at the interface of the two systems where the continuous liquid flow from the LC had to be linked to the MS gas-based detection technique in vacuum. This dilemma was solved by the development of atmospheric pressure ionization (API) (Carroll et al., 1974; Horning et al., 1973) and electrospray ionization (ESI) (Yamashita and Fenn, 1984), both allowing mass spectrometric real-time analysis of the chromatograms.

One development in API is atmospheric pressure chemical ionization (APCI). Here, the LC flow is directly injected into a vaporization tube, where it hits a high-pressure stream of nitrogen leading to nebulization. The solvent is then evaporated at temperatures of $400{ }^{\circ} \mathrm{C}$ and directed towards a high voltage corona needle were discharge and ionization processes take place. This allows two-step ionization similar to $\mathrm{Cl}$, i.e. high voltage induces first ionizing solvent molecules in the gas which then ionize the analytes (Bruins, 1991). The latest API methodology is atmospheric pressure photo ionization (APPI) (Robb et al., 2000). The experimental strategy is similar to APCl but includes a gas-phase dopant like toluene, acetone, anisole or 
chlorobenzene which enhances the photoionization when added to the drying gas during evaporation. The evaporated LC flow then passes a discharge lamp emitting $10 \mathrm{eV}$ photons which ionize the dopant molecules forming a large number of free radicals and molecular ions. Subsequently, analyte molecules are ionized by the dopants through electron or proton transfer (Raffaelli and Saba, 2003). In contrast to these and other API techniques, ESI is based on the direct ionization of analytes from the solvent stream. The solvent stream exiting a capillary forms a fine aerosol when energized by high voltage. As the solvent evaporates from the droplets, electrostatic repulsion overcomes the surface tension leading to Coulomb fissions until all solvent is evaporated. At this point, charge carriers from the solvent like protons or metal cations are transferred, and only the charged analyte molecules remain (Iribarne, 1976). When using ESI, special attention must be drawn on the solvent composition because ion pairing and derivatization agents are critical for ionization performance (Garcia, 2005; Krusemark et al., 2009). Beyond AAD, ESI has been successfully applied to softly ionize large biomolecules (Fenn et al., 1989). In any case, the choice of ionization technique mainly depends on the polarity of the analyte, i.e. ESI is well suitable for polar molecules but less effective for the analysis of non-polar compounds where APCI and APPI might be advantageous (Niessen et al., 2006).

Independent of the ionization method of choice, MS has become the predominant mode of detection in metabolomics and for AAD in particular. With GC-MS and LC-MS, two separate techniques are widely used in the field. However, it is still a matter of debate which of these techniques is superior and can be considered as state-of-the-art "gold standard". The number of actual comparative studies for both analytics platforms is surprisingly limited given the rapidly expanding field of metabolomics.

A first conclusive study on this issue was published in 2009 by Kaspar (Kaspar et al., 2009a). Here, AAD in two batches of urinary samples via a commercial AA analyzer was compared to (i) a GC-MS method using propyl chloroformate derivatization combined with isotope-labeled internal standards (see also Chapter 5), and (ii) an interesting LC-MS/MS method employing for the first time isobaric tagging by $\mathrm{ITRAQ} \AA$ in the analysis of physiological AAs. Separation and analyses were performed on commercially available systems ( $A A$ analyzer: Biochrom 30; GC-MS: Agilent 6890/5975 with a ZB-AAA column; RPLC-MS/MS: Agilent 1100 Series LC system with an Applied Biosystems $C_{18}$ column coupled to an Applied Biosystems API 3200 $\mathrm{MS}$ with one-transition multiple reaction monitoring (MRM)). Total run times varied between $130 \mathrm{~min}$ for the AA analyzer and 20 and $25 \mathrm{~min}$ for GC-MS and iTRAQ®-LC-MS/MS, respectively. The $A A$ analyzer also required higher concentrations as Lower Limit of Quantification (LLOQ; $2-3 \mu \mathrm{mol} / \mathrm{L}$ ) compared to GC-MS (0.3-30 $\mu \mathrm{mol} / \mathrm{L})$ and ITRAQ®-LCMS/MS (0.5-50 $\mu \mathrm{mol} / \mathrm{L})$. LC-MS/MS was superior in overall amenability of AAs covering 42 of 45 analytes, closely followed by the AA analyzer with 40. GC-MS only discriminated 26 of the 
analytes, i.e. detection was strongly limited by either thermic instability (Arg) or low vapor pressure (e.g. phosphoserine). AA analyzer and GC-MS were comparable in terms of reproducibility, with an average technical error (\% TE) of $7.59 \pm 4.96 \%$ and $8.28 \pm 6.64 \%$, respectively, for the second batch of samples. In the case of GC-MS, reproducibility was higher only if isotope-labeled internal standards were added (5.87 $\pm 3.59 \%$ vs. $13.03 \pm 8.31 \%$ TE for AAs without standard, for which the nearest eluting IS was used as references). Despite intrinsically available isotope-labeled internal standards, iTRAQ®-LC-MS/MS initially performed worst with a TE of $30.38 \pm 19.16 \%$. This could predominantly be attributed to an excess of MRM transitions acquired within one of four predefined time windows. The authors argued that this shortcoming could be alleviated by implementation of a new MRM schedule which exclusively monitors each AA within the time of its expected elution. Both GC-MS and LC-MS/MS were thus considered as excellent alternatives to the AA analyzer, with GC-MS having the advantage of full automation, short run time and high precision, while ITRAQ®-LC-MS/MS made more AAs amenable to analysis. The methodology described in this study was later adopted in AA Analysis: Methods and Protocols (Dettmer et al., 2012).

An independent, more recent study on GC-MS and LC-MS performance in AAD was undertaken by Krumpochova and co-workers, who presented a detailed inter platform comparison of GC-MS, HPLC-MS, and HILIC-MS (Krumpochova et al., 2015). Separation and analyses were again based on the use of commercially available systems (GC-MS: Shimadzu GC-2010 gas chromatograph with a ZB-AAA column coupled to a GCMS-QP2010 Plus EI-MS; RPLC-MS: Agilent 1100 Series LC system with a Zorbax Eclipse XCB- $\mathrm{C}_{18}$ column coupled to an AC-Sciex API 3000; HILIC-MS: Shimadzu Nexera LC30 AD LC system with a Phenomenex Luna- $\mathrm{NH}_{2}$ column coupled to a Shimadzu LCMS-8030 ESI-MS). Samples for GC-MS and RPLC-MS were subjugated to derivatization with propyl chloroformate using the EZ:faast ${ }^{\mathrm{TM}}$ amino acid analysis kit (Badawy, 2012). A method-specific optimization and determination of LODs, LLOQs, repeatability and reproducibility was first performed on a ${ }^{13} \mathrm{C},{ }^{15} \mathrm{~N}$-labeled mixture of all 20 canonical AAs as quality control (QC) to facilitate inter platform comparison. Subsequently, run times (including column equilibration) of $7 \mathrm{~min}$ for GC-MS, $20 \mathrm{~min}$ for RPLC-MS and 45 min for HILIC-MS were accomplished.

None of the methods utilized in (Krupochova et al., 2015) were able to achieve total baseline separation for all AAs of interest; GC-MS was unable to separate isoleucine/leucine and asparagine/methionine. An additional constriction in GC-MS was the invisibility of arginine due to thermal instability of the derivative. Separation of isobaric AAs was feasible via LC-MS, and further identification of non-baseline separated AAs was performed by SRMs in MS/MS. Comparable LODs were achieved with lower limits of $50 \mathrm{nM}$ in GC-MS and $\leq 100 \mathrm{nM}$ in RPLCMS for all analytes. LODs in HILIC-MS differed for particular AAs and were approximately $100 \mathrm{nM}$ for cystine, glycine and threonine and in the range of $1-30 \mathrm{nM}$ for all 
other AAs. In terms of accuracy, both LC-MS methods performed comparably well with intra/inter-day accuracies of $90-120 \%$ (RP) and $80-120 \%$ (HILIC) using ${ }^{13} \mathrm{C},{ }^{15} \mathrm{~N}$-labeled standards. GC-MS was more accurate with 99 - $105 \%$ / 83 - $115 \%$ intra-/inter-day accuracy. Linearity varied between 0.05 - $200 \mu \mathrm{M}$ (GC-MS), 0.1 - $100 \mu \mathrm{M}$ (RPLC-MS) and $0.03-100 \mu \mathrm{M}$ (HILIC-MS). The use of ${ }^{13} \mathrm{C},{ }^{15} \mathrm{~N}$-labeled internal standards allowed to expand the LLOQ sixfold for GC-MS, ten-fold for RPLC-MS and three-fold for HILIC-MS. After analysis of the QC sample, an animal tissue hydrolysate (Primatone ${ }^{\circledR}$, Sigma-Aldrich) - containing all proteinogenic AAs except arginine, glutamine and cysteine - was used as test sample. All three platforms showed similar standard deviations; however, a general underestimation of yield delivered by HILIC-MS relative to GC-/RPLC-MS was noted. In addition, RPLC-MS failed to fully separate valine and norleucine with the internal standards of the EZ:Faast kit. Analysis of valine was possible though, when using ${ }^{13} \mathrm{C},{ }^{15} \mathrm{~N}$-labeled standards. Due to the similar performance of all three platforms, intrinsic matrix effects could either be neglected or were directly corrected by using ${ }^{13} \mathrm{C},{ }^{15} \mathrm{~N}$-labeled standards. Hence, the authors concluded that all three methodologies are suited for the reproducible analysis of AAs, with the GC-MS setup being most precise and considered best for a targeted approach of selected AAs. HILIC-MS as the most versatile technique can separate a larger pool of hydrophilic compounds and might thus be superior for broader metabolomics studies beyond AAs. RPLC-MS, while not particularly outstanding in any category, was nevertheless the only method capable of quantifying all $A A s$ in both the QC sample and the animal tissue hydrolysate.

In conclusion, both GC-MS and LC-MS appear to perform quite well in AAD. GC-MS generally achieves excellent accuracies but derivatization of $A A s$ is essential. Combined with the high temperatures required for analysis, this reduces the number of AAs amenable to analysis. In contrast, the full spectrum of AAs is accessible by LC-MS but at the cost of higher analysis time and often only by employing derivatized AAs to enhance separation efficacy. Several newer studies have succeeded in reducing analysis time to $12-15 \mathrm{~min}$ for LC-MS of underivatized AAs by employing 2-D LC and MRM methods (Le et al., 2014; Zhou et al., 2013; Zhou et al., 2015). With a three minute (3AA) separation procedure, Nemkov (Nemkov et al., 2015) recently published the shortest protocol for highly sensitive and reproducible AAD and quantification from biological samples via LC-MS using an ultra high performance liquid chromatography (UHPLC) (Ultimate 3000, Thermo); here, separation was performed on an $\mathrm{XB}-\mathrm{C} 18$ column with $1.7 \mu \mathrm{m}$ particles by isocratic elution with $\mathrm{AcN} / \mathrm{H}_{2} \mathrm{O}(5: 95,0.1 \%$ $\mathrm{CH}_{3} \mathrm{COOH}$ ). Coupled to a QExactive MS (Thermo, San Jose, CA, USA), this setup allowed the detection and quantification of 35 AAs from three different AA standards (SD1-3, Phenomenex, Torrance, CA, USA) as well as the analysis of AAs from rat tissue samples. These results were consisted with parallel, gradient-based measurements on standard HILICMS (15 min analysis time) and an amide HILIC-MS (23 min analysis time) system, surpassing 
these standard systems in terms of signal to baseline ratios, LOD and LLOQ for the standards and delivering comparable results for relative quantitation of pancreatic cancer cell extract samples. Limitation to the 3AA method was the relatively high influence of matrix effects on linearity requiring the determination of matrix-dependent linear ranges for quantification in future applications. Nonetheless, this derivatization-free method might indeed be useful for high-throughput $A A D$ as stated by the authors, especially for routine samples in biomedical research.

\section{In focus: Potential and challenges of LC-MS based AAD}

\subsection{Sample preparation and handling}

Despite high acquisition and maintenance costs, the combination of LC with (tandem) MS (LCMS) has increasingly been utilized for AAD in recent years due to its high sensitivity and accuracy. LC-MS has become the gold standard for pesticide and drug residue analysis in environmental, food and clinical chemistry (Fang et al., 2015; Shushan, 2010; Thornalley and Rabbani, 2014; Van Eeckhaut et al., 2009). While the discrimination of analytes in UV/FLHPLC is exclusively based on the retention time, MS can differentiate even overlapping peaks by the unique fingerprint of fragmentation pattern of each molecule as detailed in chapter 3 . LC-MS can be combined with optical detectors for internal cross-check (Armstrong et al., 2007; Kaspar et al., 2009a). As technical overview, we recommend reading of the excellent 2009 article by James Pitt, an expert in LC-MS analytics and newborn screening (Pitt, 2009). We will in the following paragraphs describe the process from sampling to AA quantification via LC-MS as drafted in Fig. 5 and address major pitfalls, some of which have briefly been mentioned in the previous chapters.

Spatiotemporal representative sampling is crucial for high quality AAD. AA quantification in human plasma, for instance, requires sampling in the morning because AA concentrations in the blood follow a circadian rhythm being lowest in the morning in the absence of overnight ingestion and highest in the afternoon (Feigin et al., 1967). The sample preparation protocol for LC-MS has to be adapted for the molecules of interest, the expected concentration range and the sample matrix composition. Biological matrices such as plasma, serum, whole blood, dried blood spots, urine, liquor or tissues usually contain phospholipids, fat and/or proteins and can be delicate in handling, in particular for low concentrated analytes. These matrix constituents impair AA separation, can increase the instrument pressure and block the column. Deproteinization of the samples is essential but not trivial. The application of sulfosalicylic acid is quite common for protein precipitation, even if this technique shows a poor AA recovery and overlapping peaks due to the rather high sulfosalicylic acid signal (Aristoy and Toldra, 1991; Liu et al., 2001). Alternatives to sulfosalicylic acid are various organic solvents such as acetonitrile and/or methanol which shall best be combined with ultrafiltration. Nonetheless, 
non-precipitable compounds such as fatty acids or phospholipids remain in the sample (Ghassabian et al., 2014; Joyce et al., 2016; Nemkov et al., 2015; Van Eeckhaut et al., 2009). Defatting of samples with low lipid content can be achieved if the deproteinization is performed at $4^{\circ} \mathrm{C}$; for high lipid contents it is necessary to use unpolar solvent such as hexane or dioxane. Phospholipids can then be removed using commercially available solvent kits (Carmical and Brown, 2016). Sample preparation should further include an additional step to meet with putative matrix effects. Suitable methods are solid phase extraction (SPE), the implementation of internal, stable isotope standards, and additional derivatization and/or filtration steps.

As detailed in chapter 4, many derivatization procedures are approved for AAD via HPLC. Is derivatization therefore mandatory? Indeed, the derivatization step which is required in HPLC is not obligate for LC-MS but can of course enhance the sensitivity of AAD (Santa, 2011). Major drawback and limitation for large-scale studies is the time frame required for the derivatization reaction with risk of error (Salazar et al., 2012). AA derivatization is carried out to convert hydrophilic AAs into more hydrophobic molecules for reversed phase chromatography and reduction of matrix effects (Santa, 2011). In LC-MS, it further aims at the introduction of ionizable groups improving the sensitivity, selectivity and accuracy of the measurement; the higher molecular weight of the derivate AA leads to an enhanced signal to noise ratio (Kaspar et al., 2009b; Rydberg et al., 2009; Salazar et al., 2012). Reagents exclusively developed for rapid derivatization of small samples via LC-MS are listed in Tab. 1. Further details and alternative reagents are described elsewhere (Kaspar et al., 2008; Santa, 2011).

\subsection{Prospects and limitations of LC-MS without derivatization}

For many AAs, LC-MS without derivatization is high-speed and convenient (Armstrong et al., 2007; Joyce et al., 2016). Chaimbault and colleagues were the first to describe the parallel analysis of 20 underivatized AAs with LC-MS in the late 1990ies (Chaimbault et al., 1999). Today, the addition of ion-pairing agents to the mobile phase is a common procedure to then also apply reversed phase columns for non-derivatized AA separation; Chaimbault used trifluoroacetic acid for this purpose (Chaimbault et al., 1999). In 2007, Armstrong (Armstrong et al., 2007) could in principle detect 25 AAs without derivatization since all of them are usually well ionized. ESI (see chapter 4) as method of choice for gentle biomolecule ionization and fragmentation was applied (Kulyk et al., 2015). For improving the specificity of the measurement, a MRM protocol was engaged that allows identification of specific precursor-toproduct ion transitions (Armstrong et al., 2007). Nonetheless, a concentration step might be advised in case of low-concentrated analytes. Recently, a protocol for the sensitive detection of 18 proteinogenic AAs in natural water samples with reduced matrix effects was presented using SPE (How et al., 2014). Of note, homocysteine (HCy) which is relevant in methionine metabolism and associated with various diseases as highlighted in this review, was not 
included in previous AA panels - not because it has to be derivatized but due to other analytical challenges, e.g. the formation of dimers (homocystine) via disulfide bridges. The newborn screening highlighted in chapter 1 , for example, contains homocysteine in some countries but not others, although adapted analytical protocols for easy sample handling and fast detection have recently been published (Chambers et al., 2014; Ghassabian et al., 2014).

Despite the technical progress, LC-MS measurements are still susceptible to interference requiring adequate troubleshooting strategies. Although run times are becoming shorter, long equilibration periods for the columns to remove the accumulated ion-pairing reagent limit sample high-throughput (Chaimbault et al., 2000). The general assumption that LC-MS allows to run 30 samples (or more) per hour has been questioned by unreliable, non-reproducible results (Matuszewski et al., 2003). Indeed, elimination or shortening of the intermediate equilibration steps may cause problems during analysis reflected by shift of the peaks, double or splitted peaks and alterations in peak shapes. Besides, matrix effects - first described in 1993 by Kebarle \& Tang (Kebarle and Tang, 1993) - can manifest in similar signal falsification. The state of knowledge in matrix effects has been outlined earlier (Antignac et al., 2005; Matuszewski et al., 2003; Van Eeckhaut et al., 2009) but the underlying interrelations are still not completely understood (Fang et al., 2015). In brief, two substantial negative effects may be seen in LC-MS analysis of AAs in biological samples, namely ion suppression and ion enhancement. Both adversely affect the quality of readout (Cappiello et al., 2008). In this context, undesired interferences between co-eluting matrix and analyte at the ion source affecting analyte ionization as mentioned earlier and co-eluting matrix at the interface altering the $\mathrm{pH}$ are under discussion (Matuszewski et al., 2003; Van Eeckhaut et al., 2009). Here, the term matrix comprises either endogenous compounds from the sample matrix or exogenous compounds trespassing with sample preparation (Antignac et al., 2005; How et al., 2014; Van Eeckhaut et al., 2009). Samples undergoing ESI seem to be more frequently affected (Cappiello et al., 2008; Trufelli et al., 2011; Van Eeckhaut et al., 2009). Various strategies proposed to tackle these problems are summarized in Tab. 2.

\section{LC-MS for monitoring specific therapy-related AAs: An example}

The power of LC-MS for plasma AAs monitoring is increasingly appreciated in cancer research and therapy. Dietary or enzymotherapeutic depletion of selected (single) AAs are promising systemic treatment options for various malignant diseases as emphasized in chapter 2 . We recently found arginine withdrawal - also termed arginine-deprivation therapy (ADT) - to enhance radiosensitivity in cancer cells with high arginine demand even if they were per se non-auxotrophic for this AA; co-exposure to low doses of the arginine analogue canavanine demonstrated tumor-selective efficacy in colorectal cancer models in vitro and supported or augmented the radiosensitizing effect (Vynnytska-Myronovska et al., 2012). Current GC-MS 
methodology fails in reliable arginine quantification (Kaspar et al., 2009a; Krumpochova et al., 2015) and is thus not adequate for treatment monitoring neither in the experimental in vitro and in vivo settings nor in the clinical situation. LC-MS was considered as method of choice due to its high specificity and low detection limits. For our own studies, we developed a 20minute LC-MS/MS protocol for the simultaneous detection of the structurally related AA arginine, citrulline, ornithine and canavanine on the one hand, and for methionine and homocysteine on the other hand, which is applicable to a variety of matrices such as culture medium, plasma and tissue (Kurlishchuk et al., 2016 and unpublished data).

Proteinogenic arginine is an alkaline AA with a guanidine group; citrulline its non-proteinogenic precursor in the urea cycle carries a ureido instead of the guanidine group, and canavanine is a non-proteinogenic guanadinooxy structural analogue of arginine (Morris, 2002; Morris 2006; Morris, 2009) (Fig. 6). The chemical analogies of these AAs as well as the complexity of matrices of interest are challenging; our protocol thus includes the addition of stable isotopes as internal standard for each analyte. Deproteinization is performed using an acetonitrile/methanole mix followed by an ultrafiltration prior to sample transfer into the MS vial. The filtration step is cost-intense but should not be omitted for the benefit of an informative chromatogram. Directly after running the optimized sample preparation procedure (protein precipitation, centrifugation, filtration), a classical ion pair reagent (trifluoroacetic acid, TFA) is applied as mobile phase. The chromatographical separation is adjusted to define the retention and elution times for each analyte. A Hypercarb column (Thermo Fisher) consisting of a porous graphite packing material as recommended for highly selective AAD with LC-MS (Chaimbault et al., 2000) is utilized due to its ability to efficiently separate polar compounds. A prerequisite for successful MS measurements is the solid and sensitive detection of analytes. Here, a triple quadrupole mass spectrometer (Agilent 6410) is used with optimized MS settings like fragmentor and collision voltage for all molecules of interest. Optimal values for adjustment were defined beforehand for each individual isotope-labeled standard by monitoring the signal along an incrementally changing MS voltage to set up the final MRM method. Calibration curves were prepared by recording isotope standards with different concentrations and plotting the concentration as function of the peak ratio. Based on that, analyte concentrations in unknown samples can now be determined from each individual peak area relative to the respective isotope standard as exemplified in Fig. 6. In our setting, the lower limit of detection is in the range of $50-100 \mathrm{nmol} / \mathrm{l}$ with an injection volume of $1-2 \mu \mathrm{l}$. The same limits apply to the detection of methionine whereas homocysteine quantification turned out to be more complex and less sensitive. By introducing an additional reduction step using dithiothreitol to efficiently convert homocystine back into its monomers, homocysteine can be analyzed with a detection limit of 0.5-2 $\mu \mathrm{mol} / \mathrm{l}$ which is in the range published earlier (Hellmuth et al., 2011; Hempen et al., 2008). 
Pitfalls in the development of the protocol included peak fronting by column overload and ion suppression problems. This was solved by decreasing the amount of accumulating nonvolatile TFA in the ionizing interface and reducing the injection volume to a maximum of 1-2 $\mu$ per injection. As expected, aqueous solutions were well suited as matrix but plasma caused problems reflected by shifted retention times and slightly splitted peaks for arginine due to increased matrix effects and tailing, eventually caused by secondary retention. Inline filters for column protection and internal isotope standards unmasked and minimized matrix effects. A word of caution though - peak broadening and splitting can also result from a damaged frit or a void in the column. Storage of the internal standard solutions can also be critical. A decrease in sensitivity can to some extent be compensated by adjustment of the MS setting (EMV) but the occurrence of non-isotope amino acid peaks in chromatograms of the presumably stable isotope standards is a clear no-go. Quality control is thus obligate.

In summary, the proposed LC-MS/MS protocol turned out to be a fast, reliable and suitable approach for the quantification of related AAs such as arginine, its precursors and putative analogs in biological samples and may thus be useful not only in basic and preclinical research but also in clinical routine.

\section{Summary and Conclusions}

Amino acid metabolism is important in health and disease. AAD is thus integral part to basic and applied life sciences and associated disciplines including biotechnology, pharmacy and food chemistry. Standardized, easy handling tools for AA profiling are available or under development for various applications and are also in great demand in the field of biomedicine for the diagnosis and treatment of metabolic disorders. Amongst others, cancer should be considered as metabolic disease since carcinogenesis is accompanied by genetically and epigenetically driven alterations in central and intermediate metabolic pathways which open a window for novel theranostic concepts. Malignant cells can develop auxotrophies for nonessential and semi-essential amino acids and are often more susceptible to single AA withdrawal due to their high proliferative activity and metabolic enzyme deficiencies. The potential of $A A$ metabolic targeting via systemic dietary and enzymotherapeutic strategies in cancer research and treatment can convincingly be demonstrated with three archetypes of proteinogenic AAs: asparaginine (non-essential), arginine (semi-essential) and methionine (essential).

The need but also challenges and limitations for analyzing the respective AA in biological fluids and solid materials such as plasma or tissue from experimental targeting studies and in particular in clinical routine for treatment monitoring are recognized. In this context, classical and highly sophisticated, complementary technologies are presented and compared including different GC-MS and LC-MS settings. Technological characteristics such as accuracy, precision, complexity, speed and costs determine the choice of method. LC-MS 
facilitates the reliable, rapid, selective and precise detection of amino acids in various biological matrices of interest. By being aware of matrix effects and sample preparation steps, LC-MS is useful to even analyze some delicate AAs, their precursors and analogs with reasonable effort as exemplified for arginine, citrulline, canavanine, methionine and homocysteine which are subject in ongoing preclinical and clinical trials. 


\section{Figure Legends}

\section{Figure 1}

Schematic overview of disciplines developing and applying amino acid detection methodology in research and practice for a broad range of sample matrices

\section{Figure 2}

Chemical structures and important characteristics of the three amino acids of interest for metabolic targeting in anti-cancer therapy highlighted in this review.

\section{Figure 3}

Illustration of the asparagine-arginine-methionine metabolism network that might be altered in human diseases. This includes the urea cycle (arginine), citric acid cycle (aspartate/asparagine) and the methylation pathway \& salvage cycle, all of which are crossconnected through AA intermediates. These pathways potentially reveal novel diagnostic or therapeutic windows for metabolic targeting. AA pathway-related enzymes that are often altered in their function and/or expression in various tumor entities are highlighted in orange (figure adapted from the KEGG PATHWAY database:

http://www.genome.jp/kegg/pathway.html?sess=2764b8338258d6286de91 bbebe6faf46\#met abolism).

\section{Figure 4}

AAs of interest for the routine diagnosis and treatment of hereditary metabolic diseases (bottom) and status of AA metabolic targeting in cancer (top)

Note: (i) asparagine was the first targeted amino acid with clinical relevance in cancer; systemic enzymotherapy is in clinical routine for the treatment of acute lymphoblastic leucemia (ALL) and Non-Hodgkin lymphoma (NHL); (ii) arginine deprivation therapy (ADT) is not yet routine but in clinical trial for various (auxotrophic) tumor entities; (iii) methionine has gained clinical importance primarily as PET tracer for diagnostic purposes, i.e. as substitute for $\left[{ }^{18} \mathrm{~F}\right]$ fluorodeoxyglucose to identify microtumors and metastases in high-glycolytic organs such as the brain; the tracer is in use only at specific clinical sites for glioblastoma multiforme $\left(\mathrm{GBM}^{*}\right)$ diagnostics and radiotherapy planning; methionine reduction as treatment strategy has been considered via dietary food; enzymotherapeutic approaches are still precarious since methionine as an essential amino acid cannot be completely withdrawn from the human body. 
Abbreviations: CA - carcinoma; SCC - squamous cell carcinoma; AML - acute myeloid leukemia; ALL - acute lymphoblastic leukemia; BCAA - branched chain amino acids (Val, Leu, Ile); ArAA = aromatic amino acids (Phe, Tyr, Trp); MSUD - Maple Syrup Urine Disease

\section{Figure 5}

Sketch of LC-MS workflow for amino acid detection from sampling to measurement

Note: The addition of internal stable isotope standard(s) is common; non-isotope standards can be considered as optional step.

\section{Figure 6}

LC-MS based detection of arginine and its precursors as well as analogs, i.e. citrulline, ornithine and canavanine in a biological matrix (here shown: cell culture supernatant). Citrulline is highlighted as an example for quantification by gating the time frame of retention time and integrating the peak. Peak verification and integration is indicated for both qualifier and quantifier ions of analyte and internal standard as required for the assessment of citrulline concentration in the sample according to the given function. 


\section{References}

Abu-Rabie, P., Spooner, N., (2009) Direct quantitative bioanalysis of drugs in dried blood spot samples using a thin-layer chromatography mass spectrometer interface. Anal. Chem. 81, 10275-10284.

Abuchowski, A., Vanes, T., Palczuk, N.C., McCoy, J.R., Davis, F.F., (1979) Treatment of L5178Y tumor-bearing BDF1 mice with a non-immunogenic L-glutaminase-L-asparaginase. Cancer Treat. Rep. 63, 11271132.

Acunha, T., Simo, C., Ibanez, C., Gallardo, A., Cifuentes, A., (2016) Anionic metabolite profiling by capillary electrophoresis-mass spectrometry using a noncovalent polymeric coating. Orange juice and wine as case studies. J. Chromatogr. A 1428, 326-335.

Adams, B.A., (1935) Synthetic ion-exchange resins. J. Soc. Chem. Ind. 54.

Agrawal, V., Alpini, S.E.J., Stone, E.M., Frenkel, E.P., Frankel, A.E., (2012) Targeting methionine auxotrophy in cancer: Discovery \& exploration. Expert Opin. Biol. Ther. 12, 53-61.

Akagi, T., Ogawa, S., Dugas, M., Kawamata, N., Yamamoto, G., Nannya, Y., Sanada, M., Miller, C.W., Yung, A., Schnittger, S., Haferlach, T., Haferlach, C., Koeffler, H.P., (2009) Frequent genomic abnormalities in acute myeloid leukemia/myelodysplastic syndrome with normal karyotype. Haematologica 94 213-223.

Al Hafid, N., Christodoulou, J., (2015) Phenylketonuria: A review of current and future treatments. Transl. Pediatr. 4, 304-317.

Ali, U., Naveed, M., Ullah, A., Ali, K., Shah, S.A., Fahad, S., Mumtaz, A.S., (2016) L-asparaginase as a critical component to combat acute lymphoblastic leukaemia (ALL): A novel approach to target ALL. Eur.J. Pharm. 771, 199-210.

Alpert, A.J., (1990) Hydrophilic-interaction chromatography for the separation of peptides, nucleic acids and other polar compounds. J. Chromatogr. A 499, 177-196.

Altucci, P., Sapio, U., Coto, V., Esposito, E., De Vargas, F., (1966) The arginine deiminase enzymatic test for the diagnosis of the presence of Mycoplasma in cell cultures. J. Biol. Res. 42, 1321-1324.

Antignac, J.P., de Wasch, K., Monteau, F., De Brabander, H., Andre, F., Le Bizec, B., (2005) The ion suppression phenomenon in liquid chromatography-mass spectrometry and its consequences in the field of residue. Anal. Chim. Acta 529, 129-136.

Appel, I.M., den Boer, M.L., Meijerink, J.P.P., Veerman, A.J.P., Reniers, N.C.M., Pieters, R., (2006) Up-regulation of asparagine synthetase expression is not linked to the clinical response I-asparaginase in pediatric acute lymphoblastic leukemia. Blood 107, 4244-4249.

Arapitsas, P., Della Corte, A., Gika, H., Narduzzi, L., Mattivi, F., Theodoridis, G., (2016) Studying the effect of storage conditions on the metabolite content of red wine using HILIC LC-MS based metabolomics. Food Chem. 197, 1331-1340.

Aristoy, M.C., Toldra, F., (1991) Deproteinization techniques for HPLC amino acid analysis in fresh pork muscle and dry-cured ham. J. Agr. Food Chem. 39, 1792-1795.

Armstrong, M., Jonscher, K., Reisdorph, N.A., (2007) Analysis of 25 underivatized amino acids in human plasma using ion-pairing reversed-phase liquid chromatography/time-of-flight mass spectrometry. Rapid Commun. Mass Sp. 21, 2717-2726.

Arsenault, G.P., Dolhun, J.J., Biemann, K., (1970) Gas chromatography - chemical ionization mass spectrometry. J. Chem. Soc. Chem. Comm., 1542-1543.

Aslanian, A.M., Fletcher, B.S., Kilberg, M.S., (2001) Asparagine synthetase expression alone is sufficient to induce L-asparaginase resistance in MOLT-4 human leukaemia cells. Biochem. J. 357, 321-328.

Asselin, B., Rizzari, C., (2015) Asparaginase pharmacokinetics and implications of therapeutic drug monitoring. Leukemia Lymphoma 56, 2273-2280.

Avramis, V.I., Martin-Aragon, S., Avramis, E.V., Asselin, B.L., (2007) Pharmacoanalytical assays of Erwinia asparaginase (Erwinase) and pharmacokinetic results in high-risk acute lymphoblastic leukemia (HR ALL) patients: Simulations of Erwinase population PK-PD models. Anticancer Res. 27, 25612572.

Bach, S.J., Swaine, D., (1965) Effect of arginase on retardation of tumour growth. Brit. J. Cancer 19, 379-386.

Badawy, A.A.B., (2012) The EZ:Faast family of amino acid analysis kits: Application of the GC-FID kit for rapid determination of plasma tryptophan and other amino acids. Methods Mol. Biol. (828), 153-164.

Badiou, S., Lehmann, S., Cristol, J.-P., Bellet, H. (2004) Determination of plasma amino acids by fluorescent derivatization and reversed-phase liquid chromatographic separation. Clin. Lab. 50 (3-4), 153-158.

Baghdady, Y. Z., Schug, K. A. (2016) Review of in situ derivatization techniques for enhanced bioanalysis using liquid chromatography with mass spectrometry. J. Sep. Sci. 39 (1), 102-114.

Bank, R.A., Jansen, E.J., Beekman, B., te Koppele, J.M. Amino acid analysis by reverse-phase high-performance liquid chromatography: improved derivatization and detection conditions with 9-fluorenylmethyl chloroformate. (1996) Anal. Biochem. 240 (2), 167-176.

Barash, O., Zhang, W., Halpern, J.M., Hua, Q.L., Pan, Y.Y., Kayal, H., Khoury, K., Liu, H., Davies, M.P.A., Haick, H., (2015) Differentiation between genetic mutations of breast cancer by breath volatolomics. Oncotarget 6, 44864-44876. DOI: $10.18632 /$ oncotarget.6269.

Barnes, T., Bell, K., DiSebastiano, K.M., Vance, V., Hanning, R., Russell, C., Dubin, J.A., Bahl, M., Califaretti, N., Campbell, C., Mourtzakis, M., (2014) Plasma amino acid profiles of breast cancer patients early in the trajectory of the disease differ from healthy comparison groups. Appl. Physiol. Nutr. Metab. 39, 740-744. 
Batch, B.C., Hyland, K., Svetkey, L.P., (2014) Branch chain amino acids: biomarkers of health and disease. Curr. Opin. Clin. Nutr. Metab. Care 17, 86-89.

Batool, T., Makky, E.A., Jalal, M., Yusoff, M.M., (2016) A comprehensive review on L-asparaginase and its applications. Appl. Biochem. Biotech. 178, 900-923.

Becker, S., Kortz, L., Helmschrodt, C., Thiery, J., Ceglarek, U., (2012) LC-MS-based metabolomics in the clinical laboratory. J. Chromatogr. B 883, 68-75.

Bellomaria, A., Nepravishta, R., Marchetti, M., Paci, M., (2016) Profiling proteins in nutraceutical formulations: Characterization of the constituents. Food Chem. 194, 733-739.

Ben Tanfous, M., Sharif-Askari, B., Ceppi, F., Laaribi, H., Gagne, V., Rousseau, J., Labuda, M., Silverman, L.B., Sallan, S.E., Neuberg, D., Kutok, J.L., Sinnett, D., Laverdiere, C., Krajinovic, M., (2015) Polymorphisms of asparaginase pathway and asparaginase-related complications in children with acute lymphoblastic leukemia. Clin. Cancer Res. 21, 329-334.

Bener, A., Dogan, M., Abou Azab, I., Rashed, A., Siddiqui, M., (2006) Amino acid profiles among colorectal cancer patients. Biomed. Res. 17, 149-154.

Bermudez, R., Feng, Y., Roleda, M.Y., Tatters, A.O., Hutchins, D.A., Larsen, T., Boyd, P.W., Hurd, C.L., Riebesell, U., Winder, M., (2015) Long-term conditioning to elevated $\mathrm{pCO}(2)$ and warming influences the fatty and amino acid composition of the diatom cylindrotheca fusiformis. PLOS One 10. DOI: http://dx.doi.org/10.1371/journal.pone.0123945

Bertino, J.R., Waud, W.R., Parker, W.B., Lubin, M., (2011) Targeting tumors that lack methylthioadenosine phosphorylase (MTAP) activity Current strategies. Cancer Biol. Ther. 11, 627-632.

Biemann, K., Vetter, W., (1960) Separation of peptide derivatives by gas chromatography combined with the mass spectrometric determination of the amino acid sequence. Biochem. Biophys. Res. Comm. 3 , 578-584.

Binner, A., Smit, I., Loehnertz, O., Linsenmeier, A., Grossmann, M., Treutter, D., (2013) Influence of enological measures on biogenic amines in wine. Mitt. Klosterneuburg 63, 139-158.

Blau, N., van Spronsen, F.J., Levy, H.L., (2010) Phenylketonuria. Lancet 376, 1417-1427.

Bobak, Y., Kurlishchuk, Y., Vynnytska-Myronovska, B., Grydzuk, O., Shuvayeva, G., Redowicz, M.J., KunzSchughart, L.A., Stasyk, O., (2016) Arginine deprivation induces endoplasmic reticulum stress in human solid cancer cells. Int. J. Biochem. Cell Biol. 70, 29-38.

Bolster, J.M., Vaalburg, W., Elsinga, P.H., Wynberg, H., Woldring, M.G., (1986) Synthesis of DL- 1-C-11 methionine. Appl. Radiat. Isotopes 37, 1069-1070.

Boogers, I., Plugge, W., Stokkermans, Y.Q., Duchateau, A.L. (2008) Ultra-performance liquid chromatographic analysis of amino acids in protein hydrolysates using an automated pre-column derivatisation method. J Chromatogr A. 1189 (1-2), 406-9.

Bowles, T.L., Kim, R., Galante, J., Parsons, C.M., Virudachalam, S., Kung, H.-J., Bold, R.J., (2008) Pancreatic cancer cell lines deficient in argininosuccinate synthetase are sensitive to arginine deprivation by arginine deiminase. Int. J. Cancer 123, 1950-1955.

Breuillard, C., Cynober, L., Moinard, C., (2015) Citrulline and nitrogen homeostasis: an overview. Amino Acids 47, 685-691.

Broome, J.D., (1963) Evidence that L-asparaginase of guinea pig serum is responsible for its antilymphoma effects. 2. Lymphoma 6C3HED cells cultured in a medium devoid of $L$-asparagine lose their susceptibility to effects of guinea pig serum in vivo. J. Exp. Med. 118, 121-148.

Broza, Y.Y., Mochalski, P., Ruzsanyi, V., Amann, A., Haick, H., (2015) Hybrid volatolomics and disease detection. Angewandte Chemie-International Edition 54, 11036-11048.

Broza, Y.Y., Zuri, L., Haick, H., (2014) Combined volatolomics for monitoring of human body chemistry. Sci Rep 4. DOI: $10.1038 /$ srep04611.

Bruins, A.P., (1991) Mass spectrometry with ion sources operating at atmospheric pressure. Mass Spectrom. Rev. 10, 53-77.

Butler, J.A.V., Stephen, J.M.L., (1948) An apparatus for the preparative electrophoretic separation of amino acids, peptides and proteins. Biochem. J. 42, R10-R11.

Cairns, R.A., Harris, I.S., Mak, T.W., (2011) Regulation of cancer cell metabolism. Nat. Rev. Cancer 11, 85-95.

Cao, P., Moini, M., (1995) Quantitative analysis of fluorimated ethylchloroformate derivatives of non-protein amino acids using positive and negative chemical ionization gas chromatography-mass spectometry. J. Chromatogr. A 710, 303-308.

Capiaumont, J., Legrand, C., Dousset, B., Belleville, F., Nabet, P., (1995) Arginine consumption as a monitor of mycoplasma infection of cultured cells. In Vitro Cell Dev.-An. 31, 497-498.

Cappiello, A., Famiglini, G., Palma, P., Pierini, E., Termopoli, V., Trufelli, H., (2008) Overcoming matrix effects in liquid chromatography-mass spectrometry. Anal. Chem. 80, 9343-9348.

Carducci, C., Birarelli, M., Nola, M., Antonozzi, I., (1999) Automated high-performance liquid chromatographic method for the determination of homocysteine in plasma samples. J. Chromatogr. A 846, 93-100.

Carmical, J., Brown, S., (2016) The impact of phospholipids and phospholipid removal on bioanalytical method performance. Biomed. Chromatogr. 30, 710-720.

Carroll, D.I., Dzidic, I., Stillwel.Rn, Horning, M.G., Horning, E.C., (1974) Subpicogram detection system for gasphase analysis based upon atmospheric-pressure ionization (API) mass spectrometry. Anal. Chem. 46, 706-710. 
Cascino, A., Muscaritoli, M., Cangiano, C., Conversano, L., Laviano, A., Ariemma, S., Meguid, M.M., Fanelli, F.R., (1995) Plasma amino acid imbalance in patients with lung and breast cancer. Anticancer Res. 15, 507-510.

Cavuoto, P., Fenech, M.F., (2012) A review of methionine dependency and the role of methionine restriction in cancer growth control and life-span extension. Cancer Treat. Rev. 38, 726-736.

Cellarier, E., Durando, X., Vasson, M.P., Farges, M.C., Demiden, A., Maurizis, J.C., Madelmont, J.C., Chollet, P., (2003) Methionine dependency and cancer treatment. Cancer Treat. Rev. 29, 489-499.

Chaimbault, P., Petritis, K., Elfakir, C., Dreux, M., (1999) Determination of 20 underivatized proteinic amino acids by ion-pairing chromatography and pneumatically assisted electrospray mass spectrometry. J. Chromatogr. A 855, 191-202.

Chaimbault, P., Petritis, K., Elfakir, C., Dreux, M., (2000) Ion-pair chromatography on a porous graphitic carbon stationary phase for the analysis of twenty underivatized protein amino acids. J. Chromatogr. A 870, 245-254.

Chambers, A.E., Mclntosh, N., Al-Dirbashi, O.Y., Chakraborty, P., (2014) Homocysteine analysis in dried blood spots by LC-MS/MS as a second tier test for homocystinuria. Clin. Biochem. 47, 1-6.

Chaves Das Neves, H.J., (1982) Capillary gas chromatography of amino acids, including asparagine and glutamine: sensitive gas chromatogaphic-mass spectrometric and selected ion monitoring gas chromatographic-mass spectrometric detection of the N,O(S)-tert-butyldimethylsilyl derivatives. J. Chromatogr. A 392, 249-258.

Chen, B.-M., Ling-Wei, X., Rui-Qin, Z., (1997) Determination of NG,NG-dimethylarginine in human plasma by high-performance liquid chromatography. J. Chromatogr. B 692, 467-471.

Cheng, F., Wang, Z., Huang, Y., Duan, Y., Wang, X., (2015) Investigation of salivary free amino acid profile for early diagnosis of breast cancer with ultra performance liquid chromatography-mass spectrometry. Clin. Chim. Acta 447, 23-31.

Cobo Dols, M., Dominguez Lopez, M., Ramirez Plaza, C., Perez Miranda, E., Gil Calle, S., Villar Chamorro, E., Ales Diaz, I., Montesa Pino, A., Alcaide Garcia, J., Gutierrez Calderon, V., (2006) Specific alterations in the serum amino acid profile of patients with lung cancer and head and neck cancer. Oncologia (Madrid) 29, 17-24.

Comar, D., Cartron, J.C., Maziere, M., Marazano, C., (1976) Labeling and metabolism of methionine-methyl-C-11. Eur. J. Nucl. Med. 1, 11-14.

Consden, R., Gordon, A.H., Martin, A.J.P., (1944) Qualitative analysis of proteins: a partition chromatographic method using paper. Biochem. J. 38, 224-232.

Curis, E., Crenn, P., Cynober, L., (2007) Citrulline and the gut. Curr Opin Clin Nutr Metab Care 10, 620-626.

d'Amore, F., Gaulard, P., Truemper, L., Corradini, P., Kim, W.S., Specht, L., Pedersen, M.B., Ladetto, M., Comm, E.G., (2015) Peripheral T-cell lymphomas: ESMO Clinical Practice Guidelines for diagnosis, treatment and follow-up. Ann. Oncol. 26, V108-V115.

Dang, C.V., (2012) Links between metabolism and cancer. Gene. Dev. 26, 877-890.

Day, D.T., (1897) A suggestion as to the origin of pennsylvania petroleum. Proc. Am. Phil. Soc. 36, 112-115.

Day, D.T., (1903) Experiments on the diffusion of crude petroleum through fuller's earth. Science 17, 1007-1008.

Degrell, I., Hellsing, K., Nagy, E., Niklasson, F., (1989) Amino acid concentrations in cerebrospinal fluid in presenile and senile dementia of Alzheimer type and multi-infarct dementia. Arch. Gerontol. Geriat. 9, 123-135.

Delage, B., Luong, P., Maharaj, L., O'Riain, C., Syed, N., Crook, T., Hatzimichael, E., Papoudou-Bai, A., Mitchell, T.J., Whittaker, S.J., Cerio, R., Gribben, J., Lemoine, N., Bomalaski, J., Li, C.F., Joel, S., Fitzgibbon, J., Chen, L.T., Szlosarek, P.W., (2012) Promoter methylation of argininosuccinate synthetase-1 sensitise lymphomas to arginine deiminase treatment, autophagy and caspasedependent apoptosis. Cell Death Dis. 3. DOI: 10.1038/cddis.2012.83

Dempster, A.J., (1918) A new method of positive ray analysis. Phys. Rev. 11, 316-325.

Dempster, A.J., (1921) Positive ray analysis of lithium and magnesium. Phys. Rev. 18, 415-422.

Dettmer, K., Stevens, A.P., Fagerer, S.R., Kaspar, H., Oefner, P.J., (2012) Amino acid analysis in physiological samples by GC-MS with propyl chloroformate derivatization and iTRAQ-LC-MS/MS. Amino Acid Analysis: Methods and Protocols 828, 165-181.

Dillon, B.J., Prieto, V.G., Curley, S.A., Ensor, C.M., Holtsberg, F.W., Bomalaski, J.S., Clark, M.A., (2004) Incidence and distribution of argininosuccinate synthetase deficiency in human cancers - A method for identifying cancers sensitive to arginine deprivation. Cancer 100, 826-833.

Dolowy, M., Pyka, A., (2014) Application of TLC, HPLC and GC methods to the study of amino acid and peptide enantiomers: a review. Biomed. Chromatogr. 28, 84-101.

Dores, G.M., Devesa, S.S., Curtis, R.E., Linet, M.S., Morton, L.M., (2012) Acute leukemia incidence and patient survival among children and adults in the United States, 2001-2007. Blood 119, 34-43.

Douer, D., Yampolsky, H., Cohen, L.J., Watkins, K., Levine, A.M., Periclou, A.P., Avramis, V.I., (2007) Pharmacodynamics and safety of intravenous pegaspargase during remission induction in adults aged 55 years or younger with newly diagnosed acute lymphoblastic leukemia. Blood 109, 27442750.

Drew, C.M., McNesby, J.R., Smith, S.R., Gordon, A.S., (1956) Application of vapor phase chromatography to mass spectrometer analysis. Anal. Chem. 28, 979-983.

Dreyling, M., Thieblemont, C., Gallamini, A., Arcaini, L., Campo, E., Hermine, O., Kluin-Nelemans, J.C., Ladetto, M., Le Gouill, S., lannitto, E., Pileri, S., Rodriguez, J., Schmitz, N., Wotherspoon, A., Zinzani, P., Zucca, E., (2013) ESMO Consensus conferences: guidelines on malignant lymphoma. part 2: 
marginal zone lymphoma, mantle cell lymphoma, peripheral T-cell lymphoma. Ann. Oncol. 24, 857877.

Dübbers, A., Wurthwein, G., Muller, H.J., Schulze-Westhoff, P., Winkelhorst, M., Kurzknabe, E., Lanvers, C., Pieters, R., Kaspers, G.J.L., Creutzig, U., Ritter, J., Boos, J., (2000) Asparagine synthetase activity in paediatric acute leukaemias: AML-M5 subtype shows lowest activity. Brit. J. Haematol. 109, 427429.

Durando, X., Farges, M.-C., Buc, E., Abrial, C., Petorin-Lesens, C., Gillet, B., Vasson, M.-P., Pezet, D., Chollet, P., Thivat, E., (2010) Dietary methionine restriction with FOLFOX regimen as first line therapy of metastatic colorectal cancer: A feasibility study. Oncology 78, 205-209.

Durando, X., Thivat, E., Farges, M.-C., Cellarier, E., D'Incan, M., Demidem, A., Vasson, M.-P., Barthomeuf, C., Chollet, P., (2008) Optimal methionine-free diet duration for nitrourea treatment: A phase I clinical trial. Nutr. Cancer 60, 23-30.

Eaton, D.F., (1988) International union of pure and applied chemistry organic chemistry division commission on photochemistry. J. Photoch. Photobio. B 2, 523-531.

Edman, P., (1950) Method for determination of the amino acid sequence in peptides. Acta Chem. Scand. 4, 283293.

Efsa, (2011) Scientific Opinion on risk based control of biogenic amine formation in fermented foods. accessed 04.10.16.

Ensor, C.M., Holtsberg, F.W., Bomalaski, J.S., Clark, M.A., (2002) Pegylated arginine deiminase (ADI-SS $\operatorname{PEG}(20,000)(\mathrm{mw}))$ inhibits human melanomas and hepatocellular carcinomas in vitro and in vivo. Cancer Res. 62, 5443-5450.

Epner, D.E., Morrow, S., Wilcox, M., Houghton, J.L., (2002) Nutrient intake and nutritional indexes in adults with metastatic cancer on a phase I clinical trial of dietary methionine restriction. Nutr. Cancer 42, 158 166.

Evans, C., Dunstan, R.H., Rothkirch, T., Roberts, T.K., Reichelt, K.L., Cosford, R., Deed, G., Ellis, L.B., Sparkes, D.L., (2008) Altered amino acid excretion in children with autism. Nutr. Neurosci. 11, 9-17.

Fan, J., Hong, J., Hu, J.-D., Chen, J.-L., (2012) lon chromatography based urine amino Acid profiling applied for diagnosis of gastric cancer. Gastroenterol. Res. Pract. 2012, 474907. DOI: http://dx.doi.org/10.1155/2012/474907

Fang, N., Yu, S., Ronis, M.J.J., Badger, T.M., (2015) Matrix effects break the LC behavior rule for analytes in LCMS/MS analysis of biological samples. Exp. Biol. Med. 240, 488-497.

Feigin, R.D., Klainer, A.S., Beisel, W.R., (1967) Circadian periodicity of blood amino acids in adult men. Nature 215, 512-514.

Fenn, J.B., Mann, M., Meng, C.K., Wong, S.F., Whitehouse, C.M., (1989) Electrospray ionization for mass spectrometry of large biomolecules. Science 246, 64-71.

Feng, X. S., Chowbay, B., Chen, W. N., Ching, C. B. (2011) ITRAQ-Coupled 2-D LC-MS/MS analysis of differentially expressed serum proteins in nasopharyngeal carcinoma clinical samples: Potential in biomarker discovery. J. Med. Imaging Health Inform. 1 (2), 177-183.

Fenske, J.D., Kenny, G.E., (1976) Role of arginine deiminase in growth of mycoplasma hominis. J. Bacteriol. 126, 501-510.

Ferlay, J., Soerjomataram, I., Dikshit, R., Eser, S., Mathers, C., Rebelo, M., Parkin, D.M., Forman, D., Bray, F., (2015) Cancer incidence and mortality worldwide: Sources, methods and major patterns in GLOBOCAN 2012. Int. J. Cancer 136, E359-E386.

Feun, L., You, M., Wu, C.J., Kuo, M.T., Wangpaichitr, M., Spector, S., Savaraj, N., (2008) Arginine deprivation as a targeted therapy for cancer. Curr. Pharm. Design 14, 1049-1057.

Feun, L.G., Kuo, M.T., Savaraj, N., (2015) Arginine deprivation in cancer therapy. Curr. Opin. Clin. Nutr. Metab. Care 18, 78-82.

Fine, B.M., Kaspers, G.J.L., Ho, M., Loonen, A.H., Boxer, L.M., (2005) A genome-wide view of the in vitro response to $L$-asparaginase in acute lymphoblastic leukemia. Cancer Res. 65, 291-299.

Fitian, A.I., Nelson, D.R., Liu, C., Xu, Y., Ararat, M., Cabrera, R., (2014) Integrated metabolomic profiling of hepatocellular carcinoma in hepatitis C cirrhosis through GC/MS and UPLC/MS-MS. Liver Int. 34, 1428-1444.

Fitzmaurice, C., Dicker, D., Pain, A., Hamavid, H., Moradi-Lakeh, M., Maclntyre, M.F., Allen, C., Hansen, G., Woodbrook, R., Wolfe, C., Hamadeh, R.R., Moore, A., Werdecker, A., Gessner, B.D., Te Ao, B., McMahon, B., Karimkhani, C., Yu, C., Cooke, G.S., Schwebel, D.C., Carpenter, D.O., Pereira, D.M., Nash, D., Kazi, D.S., De Leo, D., Plass, D., Ukwaja, K.N., Thurston, G.D., Yun Jin, K., Simard, E.P., Mills, E., Park, E.-K., Catala-Lopez, F., deVeber, G., Gotay, C., Khan, G., Hosgood, H.D., 3rd, Santos, I.S., Leasher, J.L., Singh, J., Leigh, J., Jonas, J.B., Jonas, J., Sanabria, J., Beardsley, J., Jacobsen, K.H., Takahashi, K., Franklin, R.C., Ronfani, L., Montico, M., Naldi, L., Tonelli, M., Geleijnse, J., Petzold, M., Shrime, M.G., Younis, M., Yonemoto, N., Breitborde, N., Yip, P., Pourmalek, F., Lotufo, P.A., Esteghamati, A., Hankey, G.J., Ali, R., Lunevicius, R., Malekzadeh, R., Dellavalle, R., Weintraub, R., Lucas, R., Hay, R., Rojas-Rueda, D., Westerman, R., Sepanlou, S.G., Nolte, S., Patten, S., Weichenthal, S., Abera, S.F., Fereshtehnejad, S.-M., Shiue, I., Driscoll, T., Vasankari, T., Alsharif, U., Rahimi-Movaghar, V., Vlassov, V.V., Marcenes, W.S., Mekonnen, W., Melaku, Y.A., Yano, Y., Artaman, A., Campos, I., MacLachlan, J., Mueller, U., Kim, D., Trillini, M., Eshrati, B., Williams, H.C., Shibuya, K., Dandona, R., Murthy, K., Cowie, B., Amare, A.T., Antonio, C.A., Castaneda-Orjuela, C., van Gool, C.H., Violante, F., Oh, I.-H., Deribe, K., Soreide, K., Knibbs, L., Kereselidze, M., Green, M., Cardenas, R., Roy, N., Tillmann, T., Tillman, T., Li, Y., Krueger, H., Monasta, L., Dey, S., Sheikhbahaei, S., Hafezi-Nejad, N., Kumar, G.A., 
Sreeramareddy, C.T., Dandona, L., Wang, H., Vollset, S.E., Mokdad, A., Salomon, J.A., Lozano, R., Vos, T., Forouzanfar, M., Lopez, A., Murray, C., Naghavi, M., Global Burden of Disease Cancer, C., (2015) The Global Burden of Cancer 2013. JAMA Oncol. 1, 505-527.

Friedman, M.a., (1974) Stoichiometry of formation of Ruhemann's purple in the ninhydrin reaction. Bioorg. Chem. 3, 267-280.

Fujita, T., Yanaga, K., (2007) Association between glutamine extraction and release of citrulline and glycine by the human small intestine. Life Sci. 80, 1846-1850.

Fukutake, N., Ueno, M., Hiraoka, N., Shimada, K., Shiraishi, K., Saruki, N., Ito, T., Yamakado, M., Ono, N., Imaizumi, A., Kikuchi, S., Yamamoto, H., Katayama, K., (2015) A novel multivariate index for pancreatic cancer detection based on the plasma free amino acid profile. PLOS One 10. DOI: http://dx.doi.org/10.1371/journal.pone.0132223

Fultang, L., Vardon, A., De Santo, C., Mussai, F., (2016) Molecular basis and current strategies of therapeutic arginine depletion for cancer. Int. J. Cancer 139, 501-509.

Galli, F., (2007) Amino acid and protein modification by oxygen and nitrogen species. Amino Acids 32, 497-499.

Gao, X.Z., Ma, Q.Y., Zhu, H.L., (2015) Distribution, industrial applications, and enzymatic synthesis of D-amino acids. Appl. Microbiol. Biotech. 99, 3341-3349.

Garcia Alvarez-Coque, M.C., Medina Hernandez, M.J., Villanueva Camanas, R.M., Mongay Fernandez, C., (1989) Formation and instability of o-phthalaldehyde derivatives of amino acids. Anal. Biochem. $178,1-7$.

Garcia, M.C., (2005) The effect of the mobile phase additives on sensitivity in the analysis of peptides and proteins by high-performance liquid chromatography-electrospray mass spectrometry. J. Chromatogr. B 825, 111-123.

Gasparri, R., Santonico, M., Valentini, C., Sedda, G., Borri, A., Petrella, F., Maisonneuve, P., Pennazza, G., D'Amico, A., Di Natale, C., Paolesse, R., Spaggiari, L., (2016) Volatile signature for the early diagnosis of lung cancer. J. Breath Res. 10. DOl: 10.1088/1752-7155/10/1/016007.

Gehrke, C.W., Nakamoto, H., Zumwalt, R.W., (1969) Gas liquid chromatography of protein amino acid trimethylsilyl derivatives. J. Chromatogr. 45, 24-51.

Gehrke, C.W., Zumwalt, R.W., Wall, L.L., (1968) Gas liquid chromatography of protein amino acids separation factors. J. Chromatogr. 37, 398-413.

Ghaffari, P., Mardinoglu, A., Nielsen, J., (2015) Cancer metabolism: A modeling perspective. Front. Physiol. 6, 9.

Ghassabian, S., Rethwan, N.S.A., Griffiths, L., Smith, M.T., (2014) Fully validated LC-MS/MS method for quantification of homocysteine concentrations in samples of human serum: A new approach. J. Chromatogr. B 972, 14-21.

Giesbertz, P., Daniel, H., (2016) Branched-chain amino acids as biomarkers in diabetes. Curr. Opin. Clin. Nutr. Metab. Care 19, 48-54.

Glaudemans, A.W.J.M., Enting, R.H., Heesters, M.A.A.M., Dierckx, R.A.J.O., van Rheenen, R.W.J., Walenkamp, A.M.E., Slart, R.H.J.A., (2013) Value of C-11-methionine PET in imaging brain tumours and metastases. Eur. J. Nucl. Med. Mol. Imaging 40, 615-635.

Gohlke, R.S., (1959) Time-of-flight mass spectrometry and gas liquid partition chromatography. Anal. Chem. 31, 535-541.

Golay, M.J.E., (1957) Vapor phase chromatography and telegrapher's equation. Anal. Chem. 29, 928-932.

Goldfarb, A.R., Saidel, L.J., Mososvich, E., (1951) The ultraviolet absorption spectra of proteins. J. Biol. Chem. 193, 397-404.

Gong, H., Zolzer, F., von Recklinghausen, G., Havers, W., Schweigerer, L., (2000) Arginine deiminase inhibits proliferation of human leukemia cells more potently than asparaginase by inducing cell cycle arrest and apoptosis. Leukemia 14, 826-829.

Gordon, A.H., Martin, A.J.P., Synge, R.L.M., (1943) Partition chromatography in the study of protein constituents. Biochem. J. 37, 79-86.

Grecoa, S., Danysz, W., Zivkovic, A., Gross, R., Stark, H. (2013) Microdialysate analysis of monoamine neurotransmitters--a versatile and sensitive LC-MS/MS method. Anal. Chim. Acta 771, 65-72.

Gueli, M.C., Taibi, G., (2013) Alzheimer's disease: amino acid levels and brain metabolic status. Neurol. Sci. 34, 1575-1579.

Guo, Y., (2015) Recent progress in the fundamental understanding of hydrophilic interaction chromatography (HILIC). Analyst 140, 6452-6466.

Haley, E.E., Fischer, G.A., Welch, A.D., (1961) Requirement for L-asparagine of mouse leukemia cells L5178Y in culture. Cancer Res. 21, 532-536.

Halpern, B.C., Clark, B.R., Hardy, D.N., Halpern, R.M., Smith, R.A., (1974) Effect of replacement of methionine by homocystine on survival of malignant and normal adult mammalian cells in culture. Proc. Natl. Acad. Sci. USA 71, 1133-1136.

Han, R.-Z., Xu, G.-C., Dong, J.-J., Ni, Y., (2016) Arginine deiminase: recent advances in discovery, crystal structure, and protein engineering for improved properties as an anti-tumor drug. Appl. Microbiol. Biotech. 100, 4747-4760.

Harris, J.M., Chess, R.B., (2003) Effect of pegylation on pharmaceuticals. Nat. Rev. Drug Discov. 2, $214-221$.

Haskell, C.M., Canellos, G.P., Leventha.Bg, Carbone, P.P., Block, J.B., Serpick, A.A., Selawry, O.S., (1969) LAsparaginase - Therapeutic and toxic effects in patients with neoplastic disease. New. Engl. J. Med. 281, 1028-1034. 
Hellmuth, C., Koletzko, B., Peissner, W., (2011) Aqueous normal phase chromatography improves quantification and qualification of homocysteine, cysteine and methionine by liquid chromatography-tandem mass spectrometry. J. Chromatogr. B 879, 83-89.

Hellwig, M., Henle, T., (2014) Baking, ageing, diabetes: A short history of the Maillard Reaction. Angew. Chem. Int. Edit. 53, 10316-10329.

Hempen, C., Wanschers, H., Veer, G.v.d.S., (2008) A fast liquid chromatographic tandem mass spectrometric method for the simultaneous determination of total homocysteine and methylmalonic acid. Anal. Bioanal. Chem. 391, 263-270.

Hermanova, I., Zaliova, M., Trka, J., Starkova, J., (2012) Low expression of asparagine synthetase in lymphoid blasts precludes its role in sensitivity to L-asparaginase. Exp. Hematol. 40, 657-665.

Hijiya, N., van der Sluis, I.M., (2016) Asparaginase-associated toxicity in children with acute lymphoblastic leukemia. Leukemia Lymphoma 57, 748-757.

Hirayama, A., Kami, K., Sugimoto, M., Sugawara, M., Toki, N., Onozuka, H., Kinoshita, T., Saito, N., Ochiai, A., Tomita, M., Esumi, H., Soga, T., (2009) Quantitative metabolome profiling of colon and stomach cancer microenvironment by capillary electrophoresis time-of-flight mass spectrometry. Cancer Res. 69, 4918-4925.

Hirschhaeuser, F., Sattler, U.G.A., Mueller-Klieser, W., (2011) Lactate: A metabolic key player in cancer. Cancer Res. 71, 6921-6925.

Hoffman, R.M., (2015) Development of recombinant methioninase to target the general cancer-specific metabolic defect of methionine dependence: a 40-year odyssey. Expert Opin. Biol. Ther. 15, 21-31.

Hoffman, R.M., Jacobsen, S.J., Erbe, R.W., (1978) Reversion to methionine indipendence by malignant rat and SV40-transformed human fibroblasts. Biochem. Biophys. Res. Comm. 82, 228-234.

Holmes, J.C., Morrell, F.A., (1957) Oscillographic mass spectrometric monitoring of gas chromatography. Appl. Spectrosc. 11, 86-87.

Holzgrabe, U., Nap, C.-J., Beyer, T., Almeling, S., (2010) Alternatives to amino acid analysis for the purity control of pharmaceutical grade L-alanine. J. Sep. Sci. 33, 2402-2410.

Horning, E.C., Horning, M.G., Carroll, D.I., Dzidic, I., Stillwell, R.N., (1973) New picogram detection system based on a mass spectrometer with an external ionization source at atmospheric pressure. Anal. Chem. 45, 936-943.

Horowitz, B., Madras, B.K., Meister, A., Old, L.J., Boyse, E.A., Stockert, E., (1968) Asparagine synthetase activity of mouse leukemias. Science 160, 533-535.

Horsman, M.R., Vaupel, P., (2016) Pathophysiological basis for the formation of the tumor microenvironment. Front. Oncol. 6. DOI: http://dx.doi.org/10.3389/fonc.2016.00066

How, Z.T., Busetti, F., Linge, K.L., Kristiana, I., Joll, C.A., Charrois, J.W.A., (2014) Analysis of free amino acids in natural waters by liquid chromatography-tandem mass spectrometry. J. Chromatogr. A 1370, 135146.

Howard, G.A., Martin, A.J.P., (1950) The separation of the C12-C18 fatty acids by reversed-phase partition chromatography. Biochem. J. 46, 532-538.

Hu, J., Cheung, N.-K.V., (2009) Methionine depletion with recombinant methioninase: In vitro and in vivo efficacy against neuroblastoma and its synergism with chemotherapeutic drugs. Int. J. Cancer 124, 17001706.

Huang, Z.-H., Wang, J., Gage, D.A., Throck Watson, J., Sweeley, C.C., Hušek, P., (1993) Characterization of Nethoxycarbonyl ethyl esters of amino acids by mass spectrometry. J. Chromatogr. A 635, 271-281.

Hušek, P., (1991) Amino acid derivatization and analysis in five minutes. FEBS Lett. 280, 354-356.

Hušek, P., (1998) Chloroformates in gas chromatography as general purpose derivatizing agents. J. Chromatogr. B 717, 57-91.

Hušek, P., Šimek, P., Hartvich, P., Zahradníčková, H., (2008) Fluoroalkyl chloroformates in treating amino acids for gas chromatographic analysis. J. Chromatogr. A 1186, 391-400.

Hušek, P., Švagera, Z., Hanzlíková, D., Řimnáčová, L., Zahradníčková, H., Opekarová, I., Šimek, P., (2016) Profiling of urinary amino-carboxylic metabolites by in-situ heptafluorobutyl chloroformate mediated sample preparation and gas chromatography-mass spectrometry. J. Chromatogr. A 1443, 211-232.

Husson, A., Brasse-Lagnel, C., Fairand, A., Renouf, S., Lavoinne, A., (2003) Argininosuccinate synthetase from the urea cycle to the citrulline-NO cycle. Eur. J. Biochem. 270, 1887-1899.

Hutson, R.G., Kitoh, T., Moraga Amador, D.A., Cosic, S., Schuster, S.M., Kilberg, M.S., (1997) Amino acid control of asparagine synthetase: Relation to asparaginase resistance in human leukemia cells. Am. J. Physiol. 272, C1691-C1699.

IARC, (1993) Some naturally occurring substances: Food items and constituents, heterocyclic aromatic amines and mycotoxins. IARC Monographs on the Evalution of Carcinogenic Risks to Humans. https://monographs.iarc.fr/ENG/Monographs/vol56/mono56.pdf, accessed 10.07.16.

IARC, (1994) Some industrial chemicals. IARC Monographs on the Evaluation of Carcinogenic Risks to Humans. https://monographs.iarc.fr/ENG/Monographs/vol60/mono60.pdf, accessed 10.07.16.

Iler, R.K., (1953) Method of esterifying the surface of a silica substrate having a reactive silanol surface and product thereof. Patent.

Ilisz, I., Berkecz, R., Peter, A., (2006) HPLC separation of amino acid enantiomers and small peptides on macrocyclic antibiotic-based chiral stationary phases: A review. J. Sep. Sci. 29, 1305-1321.

Inagaki, S., Toyo'oka, T. (2012) Amino acid analysis via LC-MS method after derivatization with quaternary phosphonium. Amino Acid Analysis: Methods and Protocols. Humana Press Inc, 999 Riverview Dr, Ste 208, Totowa, Nj 07512-1165 USA, 47-54.

Inglis, A.S., (1964) Improved amino acid analyzer. Anal. Biochem. 7, 168-177. 
Inoue, H., Fukunaga, K., Tsuruta, Y. (2003) Determination of taurine in plasma by high-performance liquid chromatography using 4-(5,6-dimethoxy-2-phthalimidinyl)-2-methoxyphenylsulfonyl chloride as a fluorescent labeling reagent. Anal. Biochem. 319 (1), 139-142.

Iribarne, J.V., (1976) On the evaporation of small ions from charged droplets. J. Chem. Phys. 64, 2287. Irwin, W.J., Slack, J.A., (1978) Analytical pyrolysis in biomedical studies - Review. Analyst 103, 673-704. Iwamoto, S., Mihara, K., Downing, J.R., Pui, C.-H., Campana, D., (2007) Mesenchymal cells regulate the response of acute lymphoblastic leukemia cells to asparaginase. J. Clin. Invest. 117, 1049-1057.

Izzo, F., Marra, P., Beneduce, G., Castello, G., Vallone, P., De Rosa, V., Cremona, F., Ensor, C.M., Holtsberg, F.W., Bomalaski, J.S., Clark, M.A., Ng, C., Curley, S.A., (2004) Pegylated arginine deiminase treatment of patients with unresectable hepatocellular carcinoma: Results from phase I/II studies. J. Clin. Oncol. 22, 1815-1822.

Jain, M., Nilsson, R., Sharma, S., Madhusudhan, N., Kitami, T., Souza, A.L., Kafri, R., Kirschner, M.W., Clish, C.B., Mootha, V.K., (2012) Metabolite profiling identifies a key role for glycine in rapid cancer cell proliferation. Science 336, 1040-1044.

James, A.T., Martin, A.J.P., (1952) Gas liquid chromatography - The separation and micro-estimation of volatile fatty acids from formic acid to dodecanoic acid. Biochem. J. 50, 679-690.

James, A.T., Martin, A.J.P., Smith, G.H., (1952) Gas liquid partition chromatography - The separation and microestimation of ammonia and the methylamines. Biochem. J. 52, 238-242.

Jang, M., Kim, S.S., Lee, J., (2013) Cancer cell metabolism: implications for therapeutic targets. Exp. Mol. Med. 4.5 DOI:10.1038/emm.2013.85.

Jehmlich, N., Stegmaier, P., Golatowski, C., Salazar, M.G., Rischke, C., Henke, M., Volker, U., (2015) Differences in the whole saliva baseline proteome profile associated with development of oral mucositis in head and neck cancer patients undergoing radiotherapy. J. Proteomics 125, 98-103.

Jeong, J.S., Kim, S.K., Park, S.R., (2013) Amino acid analysis of dried blood spots for diagnosis of phenylketonuria using capillary electrophoresis-mass spectrometry equipped with a sheathless electrospray ionization interface. Anal. Bioanal. Chem. 405, 8063-8072.

Jiang, Z.Y., Xu, S.W., Wang, Y.Q., (2003) Chemistry for pegylation of protein and peptide molecules. Chin. J. Org. Chem. 23, 1340-1347.

Jones, A., Gladstone, B.P., Luebeck, M., Lindekilde, N., Upton, D., Vach, W., (2014) Motivational interventions in the management of $\mathrm{HbA1c}$ levels: A systematic review and meta-analysis. Prim. Care Diabetes 8 , 91-100.

Jorgenson, J.W., Lukacs, K.D., (1981) Free-zone electrophoresis in glass capillaries. Clin. Chem. 27, 1551-1553.

Jose, C., Bellance, N., Rossignol, R., (2011) Choosing between glycolysis and oxidative phosphorylation: A tumor's dilemma? BBA - Bioenergetics 1807, 552-561.

Joyce, R., Kuziene, V., Zou, X., Wang, X.T., Pullen, F., Loo, R.L., (2016) Development and validation of an ultraperformance liquid chromatography quadrupole time of flight mass spectrometry method for rapid quantification of free amino acids in human urine. Amino Acids 48, 219-234.

Judde, J.G., Frost, P., (1988) Patterns of methionine auxotrophy in normal and neoplastic cells - The methionine independence of lymphocyte mitogenesis and low-frequency of the methionine-dependent phenotype in human tumors. Cancer Res. 48, 6775-6779.

Jung, T.-Y., Min, J.-J., Bom, H.-S., Jung, S., Kim, I.-Y., Lim, S.-H., Kim, D.-Y., Kwon, S.Y., (2016) Prognostic value of post-treatment metabolic tumor volume from 11C-methionine PET/CT in recurrent malignant glioma. Neurosurg. Rev., 1-7.

Kaal, J., Lopez-Costas, O., Martinez Cortizas, A., (2016) Diagenetic effects on pyrolysis fingerprints of extracted collagen in archaeological human bones from NW Spain, as determined by pyrolysis-GC-MS. J. Archaeol. Sci. 65, 1-10.

Kaiser, E., Colescott, R.L., Bossinger, C.D., Cook, P.I., (1970) Color test for detection of free terminal amino groups in the solid-phase synthesis of peptides. Anal. Biochem. 34, 595-598.

Khalid, T., Aggio, R., White, P., Costello, B., Persad, R., Al-Kateb, H., Jones, P., Probert, C.S., Ratcliffe, N., (2015) Urinary volatile organic compounds for the detection of prostate cancer. Plos One 10. DOI: 10.1371 journal.pone.0143283.

Kami, K., Fujimori, T., Sato, H., Sato, M., Yamamoto, H., Ohashi, Y., Sugiyama, N., Ishihama, Y., Onozuka, H., Ochiai, A., Esumi, H., Soga, T., Tomita, M., (2013) Metabolomic profiling of lung and prostate tumor tissues by capillary electrophoresis time-of-flight mass spectrometry. Metabolomics 9, 444-453.

Kan, M.J., Lee, J.E., Wilson, J.G., Everhart, A.L., Brown, C.M., Hoofnagle, A.N., Jansen, M., Vitek, M.P., Gunn, M.D., Colton, C.A., (2015) Arginine deprivation and immune suppression in a mouse model of alzheimer's disease. J. Neurosci. 35, 5969-5982.

Kang, X. J., Xiao, J., Huang, X., Gu, Z. Z. (2006) Optimization of dansyl derivatization and chromatographic conditions in the determination of neuroactive amino acids of biological samples. Clin. Chim. Acta 366 (1-2), 352-356.

Kanomata, K., Mashiko, Y., (1966) Pyrolysis gas chromatography of amino acids and proteins. Nippon Kagaku Zasshi, 57-62.

Karakawa, S., Shimbo, K., Yamada, N., Mizukoshi, T., Miyano, H., Mita, M., Lindner, W., Hamase, K. (2010) Simultaneous analysis of D-alanine, D-aspartic acid, and D-serine using chiral high-performance liquid chromatography-tandem mass spectrometry and its application to the rat plasma and tissues. J. Pharm. Biomed. Anal. 115, 123-129.

Karovicova, J., Kohajdova, Z., (2005) Biogenic amines in food. Chem. Pap. 59, 70-79.

Kašička, V., (2016) Recent developments in capillary and microchip electroseparations of peptides (2013-middle 2015). Electrophoresis 37, 162-188. 
Kaspar, H., Dettmer, K., Chan, Q., Daniels, S., Nimkar, S., Daviglus, M.L., Stamler, J., Elliott, P., Oefner, P.J., (2009a) Urinary amino acid analysis: A comparison of iTRAQ (R)-LC-MS/MS, GC-MS, and amino acid analyzer. J. Chromatogr. B 877, 1838-1846.

Kaspar, H., Dettmer, K., Gronwald, W., Oefner, P.J., (2008) Automated GC-MS analysis of free amino acids in biological fluids. J. Chromatogr. B 870, 222-232.

Kaspar, H., Dettmer, K., Gronwald, W., Oefner, P.J., (2009b) Advances in amino acid analysis. Anal. Bioanal. Chem. 393, 445-452.

Kebarle, P., Tang, L., (1993) From ions in solution to ions in the gas phase - The mechanism of electrospray mass spectrometry. Anal. Chem. 65, A972-A986.

Kellner, R., Lottspeich, F., Meyer, H.E., (1994) Microcharacterization of Proteins. Chapter 5. VCH Verlagsgesellschaft, Weinheim, Germany.

Kelly, M.P., Jungbluth, A.A., Wu, B.W., Bomalaski, J., Old, L.J., Ritter, G., (2012) Arginine deiminase PEG20 inhibits growth of small cell lung cancers lacking expression of argininosuccinate synthetase. Brit. J. Cancer 106, 324-332.

Khoury, O., Ghazale, N., Stone, E., El-Sibai, M., Frankel, A.E., Abi-Habib, R.J., (2015) Human recombinant arginase I (Co)-PEG5000 HuArgl (Co)-PEG5000 -induced arginine depletion is selectively cytotoxic to human glioblastoma cells. J. Neuro-Oncol. 122, 75-85.

Kim, R.H., Coates, J.M., Bowles, T.L., McNerney, G.P., Sutcliffe, J., Jung, J.U., Gandour-Edwards, R., Chuang, F.Y.S., Bold, R.J., Kung, H.J., (2009) Arginine deiminase as a novel therapy for prostate cancer induces autophagy and caspase-independent apoptosis. Cancer Res. 69, 700-708.

Klein, G., Linser, H., (1932) Colorimetrische Methode zur quantitativen Bestimmung von Glykokoll. H-S Z. Physiol. Chem., 4-7.

Kolbe, H., (1862) Ueber die chemische Constitution des Asparagins und der Asparaginsäure. Liebigs Ann. Chem., 232-236.

Koziorowska, J., Pienkowska, K., Tautt, J., (1980) Dependence on exogenous methionine of rat sarcoma and murine leukemia cells in culture. Arch. Immunol. Ther. Ex. 28, 709-716.

Krause, I., Bockhardt, A., Neckermann, H., Henle, T., Klostermeyer, H. (1985) Simultaneous determination of amino acids and biogenic amines by reversed-phase high performance liquid chromatography. J. Chromatogr. A 715 (1), 67-79.

Kreis, W., Goodenow, M., (1978) Methionine requirement and replacement by homocysteine in tissue cultures of selected rodent and human malignant and normal cells. Cancer Res. 38, 2259-2262.

Krumpochova, P., Bruyneel, B., Molenaar, D., Koukou, A., Wuhrer, M., Niessen, W.M.A., Giera, M., (2015) Amino acid analysis using chromatography-mass spectrometry: An inter platform comparison study. J. Pharmaceut. Biomed. 114, 398-407.

Krusemark, C.J., Frey, B.L., Belshaw, P.J., Smith, L.M., (2009) Modifying the charge state distribution of proteins in electrospray ionization mass spectrometry by chemical derivatization. J. Am. Chem. Soc. Mass Spectrom. 20, 1617-1625.

Kuhn, R., Lederer, E., (1931) Zerlegung des Carotins in seine Komponenten. (Über das Vitamin des Wachstums, I. Mitteil). Ber. Deut. Chem. Ges. 64, 1349-1357.

Kuhn, R., Winterstein, A., Lederer, E., (1931) Information on xanthophyll. H-S Z. Physiol. Chem. 197, 141-160.

Kulyk, D.S., Miller, C.F., Badu-Tawiah, A.K., (2015) Reactive charged droplets for reduction of matrix effects in electrospray ionization mass spectrometry. Anal. Chem. 87, 10988-10994.

Kuo, M.T., Savaraj, N., Feun, L.G., (2010) Targeted cellular metabolism for cancer chemotherapy with recombinant arginine-degrading enzymes. Oncotarget 1, 246-251.

Kurlishchuk, Y., Vynnytska-Myronovska, B., Grosse-Gehling, P., Bobak, Y., Manig, F., Chen, O., Merker, S.R., Henle, T., Löck, S., Stange, D.E., Stasyk, O., Kunz-Schughart, L.A., (2016) Co-application of canavanine and irradiation uncouples anticancer potential of arginine deprivation from citrulline availability. Oncotarget [Epub ahead of print]. DOI: 10.18632 /oncotarget.12320.

la Marca, G., (2014) Mass spectrometry in clinical chemistry: The case of newborn screening. J. Pharmaceut. Biomed. 101, 174-182.

Labuschagne, C.F., van den Broek, N.J.F., Mackay, G.M., Vousden, K.H., Maddocks, O.D.K., (2014) Serine, but not glycine, supports one-carbon metabolism and proliferation of cancer cells. Cell Rep. 7, 12481258.

Larsen, T., Bach, L.T., Salvatteci, R., Wang, Y.V., Andersen, N., Ventura, M., McCarthy, M.D., (2015) Assessing the potential of amino acid C-13 patterns as a carbon source tracer in marine sediments: effects of algal growth conditions and sedimentary diagenesis. Biogeosciences 12, 4979-4992.

Le, N.D.B., Yazdani, M., Rotello, V.M., (2014) Array-based sensing using nanoparticles: an alternative approach for cancer diagnostics. Nanomedicine 9, 1487-1498.

Le, A., Ng, A., Kwan, T., Cusmano-Ozog, K., Cowan, T.M., (2014) A rapid, sensitive method for quantitative analysis of underivatized amino acids by liquid chromatography-tandem mass spectrometry (LCMS/MS). J. Chromatogr. B 944, 166-174.

Lee, K.-J., Lee, G.-H., Kim, H., Oh, M.-S., Chu, S., Hwang, I.J., Lee, J.-Y., Choi, A., Kim, C.-I., Park, H.-M., (2015) Determination of heterocyclic amines and acrylamide in agricultural products with liquid chromatography-tandem mass spectrometry. Toxicol. Res. 31, 255-264.

Lehotay, D.C., Hall, P., Lepage, J., Eichhorst, J.C., Etter, M.L., Greenberg, C.R., (2011) LC-MS/MS progress in newborn screening. Clin. Biochem. 44, 21-31.

Leichtle, A.B., Nuoffer, J.-M., Ceglarek, U., Kase, J., Conrad, T., Witzigmann, H., Thiery, J., Fiedler, G.M., (2012) Serum amino acid profiles and their alterations in colorectal cancer. Metabolomics 8, 643-653. 
Li, C., Zhang, G., Zhao, L., Ma, Z., Chen, H., (2016) Metabolic reprogramming in cancer cells: glycolysis, glutaminolysis, and $\mathrm{Bcl}-2$ proteins as novel therapeutic targets for cancer. World. J. Surg. Oncol. DOI: 14. 10.1007/s00018-015-2070-4

Li, Z.Y., Zhang, H.F., (2016) Reprogramming of glucose, fatty acid and amino acid metabolism for cancer progression. Cell. Mol. Life Sci. 73, 377-392.

Lineback, D.R., Coughlin, J.R., Stadler, R.H., (2012) Acrylamide in foods: A review of the science and future considerations. Ann. Rev. Food Sci. Technol. 3, 15-35.

Liu, M.i., (2001) Analysis of blood amino acids by HPLC method in: Cooper, C., Packer, N., Williams, K.: Amino acid analysis protocols. Humana Press Inc, 999 Riverview Dr, Ste 208, Totowa, Nj 07512-1165 USA.

Long, Y., Tsai, W.-B., Wangpaichitr, M., Tsukamoto, T., Savaraj, N., Feun, L.G., Kuo, M.T., (2013) Arginine deiminase resistance in melanoma cells is associated with metabolic reprogramming, glucose dependence, and glutamine addiction. Mol. Cancer Ther. 12, 2581-2590.

MacKenzie, S., Tenaschu, D., (1974) Gas liquid chromatography of N-heptafluorobutyryl isobutyl esters of amino acids. J. Chromatogr. 97, 19-24.

Maddocks, O.D.K., Berkers, C.R., Mason, S.M., Zheng, L., Blyth, K., Gottlieb, E., Vousden, K.H., (2013) Serine starvation induces stress and p53-dependent metabolic remodelling in cancer cells. Nature 493, 542-546.

Maddocks, O.D.K., Labuschagne, C.F., Adams, P.D., Vousden, K.H., (2016) Serine metabolism supports the methionine cycle and DNA/RNA methylation through de novo ATP synthesis in cancer cells. Mol. Cell 61, 210-221.

Magnusson, M., Lewis, G.D., Ericson, U., Orho-Melander, M., Hedblad, B., Engstrom, G., Ostling, G., Clish, C., Wang, T.J., Gerszten, R.E., Melander, O., (2013) A diabetes-predictive amino acid score and future cardiovascular disease. Eur. Heart J. 34, 1982-1989.

Mansour, F.R., Kirkpatrick, C.L., Danielson, N.D., (2013) Ion exclusion chromatography of aromatic acids. J. Chromatogr. Sci. 51, 655-665.

Marquez, F. J., Quesada, A. R., Sanchezjimenez, F., Decastro, I. N. (1986) Determination of 27 dansyl amino acid derivatives in biological fluids by reversed-phase high performance liquid chromatography. J. Chromatogr. 380 (2), 275-283.

Marchiq, I., Pouyssegur, J., (2016) Hypoxia, cancer metabolism and the therapeutic benefit of targeting lactate/ $/ \mathrm{H}_{+}$ symporters. J. Mol. Med. 94, 155-171.

Martens-Lobenhoffer, J., Bode-Boeger, S.M., (2014) Mass spectrometric quantification of L-arginine and its pathway related substances in biofluids: The road to maturity. J. Chromatogr. B 964, 89-102.

Martin, A.J.P., Synge, R.L.M., (1941) A new form of chromatogram employing two liquid phases I. A theory of chromatography 2. Application to the micro-determination of the higher monoamino-acids in proteins. Biochem. J. 35, 1358-1368.

Maruyama, Y., Miyagi, E., Numazaki, R., Nakanishi, T., Kataoka, F., Saruki, N., Yamamoto, H., Shinhara, A., Muramatsu, T., Takasu, M., Ito, N., Yoshida, N., Yamakado, M., Aoki, D., Hirahara, F., (2014) Usefulness of a novel biomarker based on plasma amino acid profile for early detection of ovarian cancer. Int. J. Gynecol. Cancer 24, 76-76.

Matuszewski, B.K., Constanzer, M.L., Chavez-Eng, C.M., (2003) Strategies for the assessment of matrix effect in quantitative bioanalytical methods based on HPLC-MS/MS. Anal. Chem. 75, 3019-3030.

Mauldin, J.P., Zeinali, I., Kleypas, K., Woo, J.H., Blackwood, R.S., Jo, C.-H., Stone, E.M., Georgiou, G., Frankel, A.E., (2012) Recombinant human arginase toxicity in mice is reduced by citrulline supplementation. Transl. Oncol. 5, 26-31.

Mecham, J.O., Rowitch, D., Wallace, C.D., Stern, P.H., Hoffman, R.M., (1983) The metabolic defect of methionine dependence occurs frequently in human tumor cell lines. Biochem. Biophys. Res. Comm. 117, 429434.

Mehta, B.M., Deeth, H.C., (2016) Blocked lysine in dairy products: Formation, occurrence, analysis, and nutritional implications. Compr. Rev. Food Sci. Safety 15, 206-218.

Miyagi, Y., Higashiyama, M., Gochi, A., Akaike, M., Ishikawa, T., Miura, T., Saruki, N., Bando, E., Kimura, H., Imamura, F., Moriyama, M., Ikeda, I., Chiba, A., Oshita, F., Imaizumi, A., Yamamoto, H., Miyano, H., Horimoto, K., Tochikubo, O., Mitsushima, T., Yamakado, M., Okamoto, N., (2011) Plasma free amino acid profiling of five types of cancer patients and its application for early detection. PLOS One 6. DOI: http://dx.doi.org/10.1371/journal.pone.0024143

Miyazaki, K., Takaku, H., Umeda, M., Fujita, T., Huang, W., Kimura, T., Yamashita, J., Horio, T., (1990) Potent growth inhibition of human tumor cells in culture by arginine deiminase purified from a culture medium of a mycoplasma infected cell line. Cancer Res. 50, 4522-4527.

Moore, S., Stein, W.H., (1948) Photometric ninhydrin method for use in the chromatography of amino acids. J. Biol. Chem. 176, 367-388.

Morris, C., O'Grada, C., Ryan, M., Roche, H.M., Gibney, M.J., Gibney, E.R., Brennan, L., (2012) The relationship between BMI and metabolomic profiles: A focus on amino acids. P. Nutr. Soc. 71, 634-638.

Morris, S.M., (2002) Regulation of enzymes of the urea cycle and arginine metabolism. Ann. Rev. Nutr. 22, 87105.

Morris, S.M., (2006) Arginine: Beyond protein. Am. J. Clin. Nutr. 83, 508S-512S.

Morris, S.M., Jr., (2009) Recent advances in arginine metabolism: roles and regulation of the arginases. Brit. J. Pharmacol. 157, 922-930. 
Mullen, A.R., Wheaton, W.W., Jin, E.S., Chen, P.H., Sullivan, L.B., Cheng, T., Yang, Y.F., Linehan, W.M., Chandel, N.S., DeBerardinis, R.J., (2012) Reductive carboxylation supports growth in tumour cells with defective mitochondria. Nature 481, 385-388.

Munson, M.S.B., H, F.F., (1966) Chemical ionization mass spectrometry. I. General introduction. J. Am. Chem. Soc. 88, 2621-2630.

Mutschler, E., Rochelmeyer, H., (1959) On the separation of amino acids by means of thin layer chromatography. Arch. Pharm. 292, 449-452.

Nathan, D.M., McGee, P., Steffes, M.W., Lachin, J.M., Grp, D.E.R., (2014) Relationship of glycated albumin to blood glucose and $\mathrm{HbA}(1 \mathrm{c})$ values and to retinopathy, nephropathy, and cardiovascular outcomes in the DCCT/EDIC study. Diabetes 63, 282-290.

Naushad, S.M., Jain, J.M.N., Prasad, C.K., Naik, U., Akella, R.R.D., (2013) Autistic children exhibit distinct plasma amino acid profile. Ind. J. Biochem. Biophys. 50, 474-478.

Nemkov, T., D'Alessandro, A., Hansen, K.C., (2015) Three-minute method for amino acid analysis by UHPLC and high-resolution quadrupole orbitrap mass spectrometry. Amino Acids 47, 2345-2357.

Niessen, W.M.A., Manini, P., Andreoli, R., (2006) Matrix effects in quantitative pesticide analysis using liquid chromatography-mass spectrometry. Mass Spectrom. Rev. 25, 881-899.

Niewczas, M.A., Sirich, T.L., Mathew, A.V., Skupien, J., Mohney, R.P., Warram, J.H., Smiles, A., Huang, X., Walker, W., Byun, J., Karoly, E.D., Kensicki, E.M., Berry, G.T., Bonventre, J.V., Pennathur, S., Meyer, T.W., Krolewski, A.S., (2014) Uremic solutes and risk of end-stage renal disease in type 2 diabetes: metabolomic study. Kidney Int. 85, 1214-1224.

Odn, S., von Hofsten, B., (1954) Detection of fingerprints by the ninhydrin reaction. Nature 173, 449-450.

Ortega-Heras, M., Perez-Magarino, S., Del-Villar-Garrachon, V., Gonzalez-Huerta, C., Moro Gonzalez, L.C., Guadarrama Rodriguez, A., Villanueva Sanchez, S., Gallo Gonzalez, R., Martin de la Helguera, S., (2014) Study of the effect of vintage, maturity degree, and irrigation on the amino acid and biogenic amine content of a white wine from the Verdejo variety. J. Sci. Food Agr. 94, 2073-2082.

Otter, D.E., (2012) Standardised methods for amino acid analysis of food. Brit. J. Nutr. 108, S230-S237.

Palanichamy, K., Thirumoorthy, K., Kanji, S., Gordon, N., Singh, R., Jacob, J.R., Sebastian, N., Litzenberg, K.T., Patel, D., Bassett, E., Ramasubramanian, B., Lautenschlaeger, T., Fischer, S.M., Ray-Chaudhury, A., Chakravarti, A., (2016) Methionine and kynurenine activate oncogenic kinases in glioblastoma, and methionine deprivation compromises proliferation. Clin. Cancer Res. 22, DOI: 10.1158/10780432.CCR-15-2308.

Pardee, A.B., (1974) Restriction point for control of normal animal cell proliferation. Proc. Natl. Acad. Sci. USA 71, 1286-1290.

Pastorczak, A., Fendler, W., Zalewska-Szewczyk, B., Gorniak, P., Lejman, M., Trelinska, J., Walenciak, J., Kowalczyk, J., Szczepanski, T., Mlynarski, W., Polish Pediat Leukemia, L., (2014) Asparagine synthetase (ASNS) gene polymorphism is associated with the outcome of childhood acute Iymphoblastic leukemia by affecting early response to treatment. Leukemia Res. 38, 180-183.

Patil, M.D., Bhaumik, J., Babykutty, S., Banerjee, U.C., Fukumura, D., (2016) Arginine dependence of tumor cells: targeting a chink in cancer's armor. Oncogene 10. DOI: 1038/onc.2016.37 10.1038/onc.2016.37.

Peng, H., Shen, N., Qian, L., Sun, X.L., Koduru, P., Goodwin, L.O., Issa, J.P., Broome, J.D., (2001) Hypermethylation of $\mathrm{CpG}$ islands in the mouse asparagine synthetase gene: relationship to asparaginase sensitivity in lymphoma cells. Partial methylation in normal cells. Brit. J. Cancer 85 930-935.

Perez-Miguez, R., Marina, M.L., Castro-Puyana, M., (2016) Capillary electrophoresis determination of non-protein amino acids as quality markers in foods. J. Chromatogr. A 1428, 97-114.

Peura, L., Malmioja, K., Huttunen, K., Leppanen, J., Hamalainen, M., Forsberg, M.M., Rautio, J., Laine, K., (2013) Design, synthesis and brain uptake of LAT1-targeted amino acid prodrugs of dopamine. Pharmaceut. Res. 30, 2523-2537.

Pieters, R., Appel, I., Kuehnel, H.-J., Tetzlaff-Fohr, I., Pichlmeier, U., van der Vaart, I., Visser, E., Stigter, R., (2008) Pharmacokinetics, pharmacodynamics, efficacy, and safety of a new recombinant asparaginase preparation in children with previously untreated acute lymphoblastic leukemia: a randomized phase 2 clinical trial. Blood 112, 4832-4838.

Pieters, R., Hunger, S.P., Boos, J., Rizzari, C., Silverman, L., Baruchel, A., Goekbuget, N., Schrappe, M., Pui, C.H., (2011) L-Asparaginase treatment in acute lymphoblastic leukemia. Cancer 117, 238-249.

Pietzsch, J., Bergmann, R., Kopprasch, S., (2004) Analysis of non-protein amino acids as specific markers of low density lipoprotein apolipoprotein B-100 oxidation in human atherosclerotic lesions: the use of $\mathrm{N}(\mathrm{O})$-ethoxycarbonyl trifluoroethyl ester derivatives and GC-MS. Spectroscopy 18, 177-183.

Pietzsch, J., Julius, U., Hanefeld, M., (1997a) Rapid determination of total homocysteine in human plasma by using $\mathrm{N}(\mathrm{O}, \mathrm{S})$-ethoxycarbonyl ethyl ester derivatives and gas chromatography mass spectrometry. Clin. Chem. 43, 2001-2004.

Pietzsch, J., Julius, U., Hanefeld, M., (1997b) Stable isotope ratio analysis of amino acids: The use of N(O,S)ethoxycarbonyl trifluoroethyl ester derivatives and gas chromatography mass spectrometry. Rapid Commun. Mass Sp. 11, 1835-1838.

Pietzsch, J., Nitzsche, S., Wiedemann, B., Julius, U., Leonhardt, W., Hanefeld, M., (1995) Stable isotope ratio analysis of amino acids: The use of $\mathrm{N}(\mathrm{O})$-ethoxycarbonyl ethyl ester derivatives and gas chromatography mass spectrometry. J. Mass Spectrom., S129-S135.

Pietzsch, J., Pixa, A., (1998) Determination of total homocysteine. Clin. Chem. 44, 1781-1782.

Pitt, J.J., (2009) Principles and applications of liquid chromatography-mass spectrometry in clinical biochemistry. Clin. Biochem. Rev. 30, 19-34. 
Poinsot, V., Bayle, C., Couderc, F., (2003) Recent advances in amino acid analysis by capillary electrophoresis. Electrophoresis 24, 4047-4062.

Poinsot, V., Gavard, P., Feurer, B., Couderc, F., (2010) Recent advances in amino acid analysis by CE. Electrophoresis 31, 105-121.

Poschke, I., Mao, Y., Kiessling, R., de Boniface, J., (2013) Tumor-dependent increase of serum amino acid levels in breast cancer patients has diagnostic potential and correlates with molecular tumor subtypes. J. Transl. Med. 11. DOI: 10.1186/1479-5876-11-290.

Possemato, R., Marks, K.M., Shaul, Y.D., Pacold, M.E., Kim, D., Birsoy, K., Sethumadhavan, S., Woo, H.-K., Jang, H.G., Jha, A.K., Chen, W.W., Barrett, F.G., Stransky, N., Tsun, Z.-Y., Cowley, G.S., Barretina, J., Kalaany, N.Y., Hsu, P.P., Ottina, K., Chan, A.M., Yuan, B., Garraway, L.A., Root, D.E., Mino-Kenudson, M., Brachtel, E.F., Driggers, E.M., Sabatini, D.M., (2011) Functional genomics reveal that the serine synthesis pathway is essential in breast cancer. Nature 476, 346 350.

Pourfarzam, M., Zadhoush, F., (2013) Newborn Screening for inherited metabolic disorders; news and views. J. Res. Med. Sci. 18, 801-808.

Prabhu, A., Sarcar, B., Kahali, S., Yuan, Z., Johnson, J.J., Adam, K.P., Kensicki, E., Chinnaiyan, P., (2014) Cysteine catabolism: A novel metabolic pathway contributing to glioblastoma growth. Cancer Res. 74, 787-796.

Preston, R.L., (1993) Transport of amino acids by marine invertebrates. J. Exp. Zool. 265, 410-421.

Purwaha, P., Lorenzi, P.L., Silva, L.P., Hawke, D.H., Weinstein, J.N., (2014) Targeted metabolomic analysis of amino acid response to L-asparaginase in adherent cells. Metabolomics 10, 909-919.

Shlomi, T., Fan, J., Tang, B., Kruger, W.D., Rabinowitz, J.D., (2014) Quantitation of cellular metabolic fluxes of methionine. Anal Chem. 86, 1583-1591.

Qiu, F., Chen, Y.-R., Liu, X., Chu, C.-Y., Shen, L.-J., Xu, J., Gaur, S., Forman, H.J., Zhang, H., Zheng, S., Yen, Y., Huang, J., Kung, H.-J., Ann, D.K., (2014) Arginine starvation impairs mitochondrial respiratory function in ASS1-deficient breast cancer cells. Sci. Signal. 7. DOI: 10.1126/scisignal.2004761

Qiu, F., Huang, J., Sui, M., (2015) Targeting arginine metabolism pathway to treat arginine-dependent cancers. Cancer Lett. 364, 1-7.

Rabie, M.A., Peres, C., Xavier Malcata, F., (2014) Evolution of amino acids and biogenic amines throughout storage in sausages made of horse, beef and turkey meats. Meat Sci. 96, 82-87.

Raffaelli, A., Saba, A., (2003) Atmospheric pressure photoionization mass spectrometry. Mass Spectrom. Rev. 22, 318-331.

Rai, K.P., Pradhan, H.R., Sharma, B.K., Rijal, S.K., (2013) Histamine in foods: Its safety and human health implications. J. Food Sci. Technol. Nepal 8, 1-11.

Ramakers-van Woerden, N.L., Pieters, R., Loonen, A.H., Hubeek, I., van Drunen, E., Beverloo, H.B., Slater, R.M., Harbott, J., Seyfarth, J., van Wering, E.R., Hahlen, K., Schmiegelow, K., Janka-Schaub, G.E., Veerman, A.J.P., (2000) TEL/AML1 gene fusion is related to in vitro drug sensitivity for Lasparaginase in childhood acute lymphoblastic leukemia. Blood 96, 1094-1099.

Richards, N.G.J., Kilberg, M.S., (2006) Asparagine synthetase chemotherapy. Ann. Rev. Biochem. 75, 629-654

Rigas, P.G., (2013) Post-column labeling techniques in amino acid analysis by liquid chromatography. Anal. Bioanal. Chem. 405, 7957-7992.

Robb, D.B., Covey, T.R., Bruins, A.P., (2000) Atmospheric pressure photoionisation: An ionization method for liquid chromatography-mass spectrometry. Anal. Chem. 72, 3653-3659.

Roberts, M.J., Bentley, M.D., Harris, J.M., (2012) Chemistry for peptide and protein PEGylation. Adv. Drug. Delivery Rev. 64, 116-127.

Rocklin, R.D., Pohl, C.A., (1983) Determination of carbohydrates by anion exchange chromatography with pulsed amperometric detection. J. Liq. Chromatogr. 6, 1577-1590.

Ruhemann, S., (1910a) CCXII. - Triketohydrindene hydrate. J. Chem. Soc. T. 97, 2025-2031.

Ruhemann, S., (1910b) Cyclic Di- and Triketones. J. Chem. Soc. T. 97, 1438-1449.

Rutherfurd, S., Gilani, M., Sarwar, G., (2009) Amino acid analysis. Curr. Prot. Protein Sci. Chapter 11, Unit 11.19.

Rutherfurd, S.M., Fanning, A.C., Miller, B.J., Moughan, P.J., (2015) Protein digestibility-corrected amino acid scores and digestible indispensable amino acid scores differentially describe protein quality in growing male rats. J. Nutr. 145, 372-379.

Rydberg, P., von Stedingk, H., Magner, J., Bjorklund, J., (2009) LC/MS/MS analysis of N-terminal protein adducts with improved sensitivity: A comparison of selected edman isothiocyanate reagents. Int. J. Anal. Chem. 2009, 153472-153472.

Rytting, M.E., Thomas, D.A., O'Brien, S.M., Ravandi-Kashani, F., Jabbour, E.J., Franklin, A.R., Kadia, T.M., Pemmaraju, N., Daver, N.G., Ferrajoli, A., Garcia-Manero, G., Konopleva, M.Y., Cortes, J.E., Borthakur, G., Garris, R., Cardenas-Turanzas, M., Schroeder, K., Jorgensen, J.L., Kornblau, S.M., Kantarjian, H.M., (2014) Augmented Berlin-Frankfurt-Münster Therapy in Adolescents and Young Adults (AYAs) with acute lymphoblastic leukemia (ALL). Cancer 120, 3660-3668.

Salazar, C., Armenta, J.M., Shulaev, V., (2012) An UPLC-ESI-MS/MS assay using 6-aminoquinolyl-Nhydroxysuccinimidyl carbamate derivatization for targeted amino acid analysis: Application to screening of Arabidopsis thaliana mutants. Metabolites 2, 398-428.

Santa, T., (2010) Isothiocyanates as derivatization reagents for amines in liquid chromatography/electrospray ionization-tandem mass spectrometry. Biomed. Chromatogr. 24, 915-918.

Santa, T., (2011) Derivatization reagents in liquid chromatography/electrospray ionization tandem mass spectrometry. Biomed. Chromatogr. 25, 1-10.

Santos, M.H.S., (1996) Biogenic amines: Their importance in foods. Int. J. Food. Microbiol. 29, 213-231. 
Sarwar, G., (1984) Available amino acid score for evaluating protein quality of foods. J. Assoc.Off. Ana. Chem. 67, 623-626.

Savaraj, N., Wu, C., Li, Y.-Y., Wangpaichitr, M., You, M., Bomalaski, J., He, W., Kuo, M.T., Feun, L.G., (2015) Targeting argininosuccinate synthetase negative melanomas using combination of arginine degrading enzyme and cisplatin. Oncotarget 6, 6295-6309.

Savaraj, N., You, M., Wu, C., Wangpaichitr, M., Kuo, M.T., Feun, L.G., (2010) Arginine deprivation, autophagy, apoptosis (AAA) for the treatment of melanoma. Curr. Mol. Med. 10, 405-412.

Scanlon, S.E., Glazer, P.M., (2015) Multifaceted control of DNA repair pathways by the hypoxic tumor microenvironment. DNA Repair 32, 180-189.

Schaafsma, G., (2000) The protein digestibility-corrected amino acid score. J. Nutr. 130, 1865S-1867S.

Schrappe, M., Hunger, S.P., Pui, C.-H., Saha, V., Gaynon, P.S., Baruchel, A., Conter, V., Otten, J., Ohara, A., Versluys, A.B., Escherich, G., Heyman, M., Silverman, L.B., Horibe, K., Mann, G., Camitta, B.M., Harbott, J., Riehm, H., Richards, S., Devidas, M., Zimmermann, M., (2012) Outcomes after induction failure in childhood acute lymphoblastic leukemia. New. Engl. J. Med. 366, 1371-1381

Shambaugh, G.E., (1977) Urea Biosynthesis. 1. Urea cycle and relationships to citric acid cycle. Am. J. Clin. Nutr. 30, 2083-2087.

Sherwood, R.A., Titheradge, A.C., Richards, D.A., (1990) Measurement of plasma and urine amino acids by highperformance liquid chromatography with electrochemical detection using phenylisothiocyanate derivatization. J. Chromatogr. A 528, 293-303.

Shimbo, K., Oonuki, T., Yahashi, A., Hirayama, K., Miyano, H. (2009b) Precolumn derivatization reagents for high-speed analysis of amines and amino acids in biological fluid using liquid chromatography/electrospray ionization tandem mass spectrometry. Rapid Commun. Mass Sp. 23 (10), 1483-1492.

Shimbo, K., Yahashi, A., Hirayama, K., Nakazawa, M., Miyano, H. (2009) Multifunctional and highly sensitive precolumn reagents for amino acids in liquid chromatography/tandem mass spectrometry. Anal. Chem. 81 (13), 5172-5279.

Shindo, N., Nojima, S., Fujimura, T., Taka, H., Mineki, R., Murayama, K. (1997) Separation of 18 6-aminoquinolylcarbamyl-amino acids by ion-pair chromatography. Anal. Biochem. 249 (1), 79-82.

Shingyoji, M., lizasa, T., Higashiyama, M., Imamura, F., Saruki, N., Imaizumi, A., Yamamoto, H., Daimon, T. Tochikubo, O., Mitsushima, T., Yamakado, M., Kimura, H., (2013) The significance and robustness of a plasma free amino acid (PFAA) profile-based multiplex function for detecting lung cancer. BMC Cancer 13. DOI: 10.1186/1471-2407-13-77

Shushan, B., (2010) A review of clinical diagnostic applications of liquid chromatography tandem mass spectrometry. Mass Spectrom. Rev. 29, 930-944.

Shuvayeva, G., Bobak, Y., Igumentseva, N., Titone, R., Morani, F., Stasyk, O., Isidoro, C., (2014) Single amino acid arginine deprivation triggers prosurvival autophagic response in ovarian carcinoma SKOV3. Biomed Res. Int. DOI: 10.1155/2014/505041.

Simek, P., Hušek, P., Zahradnickova, H., (2012) Heptafluorobutyl chloroformate-based sample preparation protocol for chiral and nonchiral amino acid analysis by gas chromatography. Amino Acid Analysis: Methods and Protocols 828, 137-152.

Simińska, E., Koba, M., (2016) Amino acid profiling as a method of discovering biomarkers for early diagnosis of cancer. Amino Acids. DOI: 10.1007/s00726-016-2215-2

Small, H., Stevens, T.S., Bauman, W.C., (1975) Novel ion exchange chromatographic method using conductimetric detection. Anal. Chem. 47, 1801-1809.

Stams, W., Den Boer, M., Beverloo, B., Meijerink, J., Stigter, R., van Wering, E., Janka-Schaub, G., Slater, R., Pieters, R., (2003) Sensitivity to L-asparaginase is not associated with expression levels of asparagine synthetase in $\mathrm{t}(12 ; 21)$ positive pediatric ALL. P. Am. Assoc. Canc. Res. Annu. Meet. 44, 710-710.

Stancáková, A., Civelek, M., Saleem, N.K., Soininen, P., Kangas, A.J., Cederberg, H., Paananen, J., Pihlajamaki, J., Bonnycastle, L.L., Morken, M.A., Boehnke, M., Pajukanta, P., Lusis, A.J., Collins, F.S., Kuusisto, J., Ala-Korpela, M., Laakso, M., (2012) Hyperglycemia and a common variant of GCKR are associated with the levels of eight amino acids in 9,369 finnish men. Diabetes 61, 1895-1902.

Starbuck, W.C., Busch, H., (1962) Programming system for automatic amino acid analyzer. Anal. Chem. 34, 875876.

Staudigl, M., Gersting, S.W., Danecka, M.K., Messing, D.D., Woidy, M., Pinkas, D., Kemter, K.F., Blau, N., Muntau, A.C., (2011) The interplay between genotype, metabolic state and cofactor treatment governs phenylalanine hydroxylase function and drug response. Hum. Mol. Genet. 20, 2628-2641.

Stein, W.H., Moore, S., (1948) Chromatography of amino acids on starch columns. Separation of phenylalanine, leucine, isoleucine, methionine, tyrosine, and valine. J. Biol. Chem. 176, 337-365.

Stewart, B.W., Wild, C.P., (2014) World Cancer Report 2014, IARC Nonserial Publication.

Stoll, D.R., Wang, X., Carr, P.W., (2008) Comparison of the practical resolving power of one- and twodimensional high-performance liquid chromatography analysis of metabolomic samples. Anal. Chem. 80, 268-278.

Stone, E., Chantranupong, L., Gonzalez, C., O'Neal, J., Rani, M., VanDenBerg, C., Georgiou, G., (2012a) Strategies for optimizing the serum persistence of engineered human arginase I for cancer therapy. J. Control Release 158, 171-179.

Stone, E., Paley, O., Hu, J., Ekerdt, B., Cheung, N.-K., Georgiou, G., (2012b) De novo engineering of a human cystathionine-gamma-lyase for systemic L-methionine depletion cancer therapy. ACS Chem. Biol. 7, 1822-1829. 
Stone, E.M., Glazer, E.S., Chantranupong, L., Cherukuri, P., Breece, R.M., Tierney, D.L., Curley, S.A., Iverson, B.L., Georgiou, G., (2010) Replacing Mn2+ with Co2+ in human arginase I enhances cytotoxicity toward L-arginine auxotrophic cancer cell lines. ACS Chem. Biol. 5, 797. DOI: 10.1021/cb1001813

Su, N., Pan, Y.-X., Zhou, M., Harvey, R.C., Hunger, S.P., Kilberg, M.S., (2008) Correlation between asparaginase sensitivity and asparagine synthetase protein content, but not mRNA, in acute lymphoblastic leukemia cell lines. Pediatr. Blood Cancer 50, 274-279.

Sugimura, T., Birnbaum, S.M., Winitz, M., Greenstein, J.P., (1959) Quantitative nutritional studies with water soluble, chemically defined diets. 8 . The forced feeding of diets each lacking in one essential amino acid. Arch Biochem Biophys 81, 448-455.

Sugimura, K., Ohno, T., Kusuyama, T., Azuma, I., (1992) High sensitivity of human melanoma cell lines to the growth inhibitory activity of mycoplasmal arginine deiminase in vitro. Melanoma Res. 2, 191-196.

Summar, M.L., Koelker, S., Freedenberg, D., Le Mons, C., Haberle, J., Lee, H.-S., Kirmse, B., European Registry, N., Ucdc, (2013) The incidence of urea cycle disorders. Mol. Genet. Metab. 110, 179-180.

Tamanna, N., Mahmood, N., (2015) Food processing and Maillard Reaction products: Effect on human health and nutrition. Int. J. Food Sci. 2015, 526762. DOI: 10.1155/2015/526762

Tang, D.-Q., Zou, L., Yin, X.-X., Ong, C.N., (2014) HILIC-MS for metabolomics: An attractive and complementary approach to RPLC-MS. Mass Spectrom. Rev. DOI: 10.1002/mas.21445.

Tang, X., Keenan, M.M., Wu, J., Lin, C.-A., Dubois, L., Thompson, J.W., Freedland, S.J., Murphy, S.K., Chi, J.-T., (2015) Comprehensive profiling of amino acid response uncovers unique methionine-deprived response dependent on intact creatine biosynthesis. Plos Genet 11. DOI: 10.1371/journal.pgen.1005158.

Tang, X., Keenan, M.M., Wu, J., Lin, C.-A., Dubois, L., Thompson, J.W., Freedland, S.J., Murphy, S.K., Chi, J.-T., (2015) Comprehensive profiling of amino acid response uncovers unique methionine-deprived response dependent on intact creatine biosynthesis. Plos Genetics 11. DOI: http://dx.doi.org/10.1371/journal.pgen.1005158

Tanwar, S., Bhushan, R., (2015) Enantioresolution of amino acids: A decade's perspective, prospects and challenges. Chromatographia 78, 1113-1134.

Tarbit, I., Perry, E.K., Perry, R.H., Blessed, G., Tomlinson, B.E., (1980) Hippocampal free amino acids in Alzheimers disease. J. Neurochem. 35, 1246-1249.

Tatum, J.L., Kelloff, G.J., Gillies, R.J., Arbeit, J.M., Brown, J.M., Chao, K.S.C., Chapman, J.D., Eckelman, W.C., Fyles, A.W., Giaccia, A.J., Hill, R.P., Koch, C.J., Krishna, M.C., Krohn, K.A., Lewis, J.S., Mason, R.P., Melillo, G., Padhani, A.R., Powis, G., Rajendran, J.G., Reba, R., Robinson, S.P., Semenza, G.L., Swartz, H.M., Vaupel, P., Yang, D., Croft, B., Hoffman, J., Liu, G., Stone, H., Sullivan, D., (2006) Hypoxia: Importance in tumor biology, noninvasive measurement by imaging, and value of its measurement in the management of cancer therapy. Int. J. Radiat. Biol. 82, 699-757.

Terrlink, T., van Leeuwen, P.A., Houdijk, A., (1994) Plasma amino acids determined by liquid chromatography within 17 minutes. Clin. Chem., 245-249.

Therrell, B.L., Jr., Lloyd-Puryear, M.A., Camp, K.M., Mann, M.Y., (2014) Inborn errors of metabolism identified via newborn screening: Ten-year incidence data and costs of nutritional interventions for research agenda planning. Mol. Genet. Metab. 113, 14-26.

Thivat, E., Farges, M.-C., Bacin, F., D'Incan, M., Mouret-Reynier, M.-A., Cellarier, E., Madelmont, J.-C., Vasson, M.-P., Chollet, P., Durando, X., (2009) Phase II trial of the association of a methionine-free diet with cystemustine therapy in melanoma and glioma. Anticancer Res. 29, 5235-5240.

Thornalley, P.J., Rabbani, N., (2014) Detection of oxidized and glycated proteins in clinical samples using mass spectrometry - A user's perspective. BBA - Gen. Subjects 1840, 818-829.

Tian, M.M., Zhang, J.F., Mohamed, A.C., Han, Y.Z., Guo, L.P., Yang, L., (2014) Efficient capillary electrophoresis separation and determination of free amino acids in beer samples. Electrophoresis 35, 577-584.

Tillin, T., Hughes, A.D., Wang, Q., Wurtz, P., Ala-Korpela, M., Sattar, N., Forouhi, N.G., Godsland, I.F., Eastwood, S.V., McKeigue, P.M., Chaturvedi, N., (2015) Diabetes risk and amino acid profiles: cross-sectional and prospective analyses of ethnicity, amino acids and diabetes in a South Asian and European cohort from the SABRE (Southall And Brent REvisited) Study. Diabetologia 58, 968-979.

Tiselius, A., (1937) A new apparatus for electrophoretic analysis of colloidal mixtures. T. Farad. Soc. 33, 05240530.

Tomlinson, B.K., Thomson, J.A., Bomalaski, J.S., Diaz, M., Akande, T., Mahaffey, N., Li, T., Dutia, M.P., Kelly, K., Gong, I.Y., Semrad, T., Gandara, D.R., Pan, C.-X., Lara, P.N., Jr., (2015) Phase I trial of arginine deprivation therapy with ADI-PEG 20 plus docetaxel in patients with advanced malignant solid tumors. Clin. Cancer Res. 21, 2480-2486.

Tong, W.H., Pieters, R., Hop, W.C.J., Lanvers-Kaminsky, C., Boos, J., van der Sluis, I.M., (2013) No evidence of increased asparagine levels in the bone marrow of patients with acute lymphoblastic leukemia during asparaginase therapy. Pediatr. Blood Cancer 60, 258-261.

Tong, W.H., Pieters, R., Tissing, W.J.E., van der Sluis, I.M., (2014) Desensitization protocol should not be used in acute lymphoblastic leukemia patients with silent inactivation of PEGasparaginase. Haematologica 99, e102-e104.

Troll, W., Cannan, R.K., (1953) A modified photometric ninhydrin method for the analysis of amino and imino acids. J. Biol. Chem. 200, 803-811.

Trufelli, H., Palma, P., Famiglini, G., Cappiello, A., (2011) An overview of matrix effects in liquid chromatography mass spectrometry. Mass Spectrom. Rev. 30, 491-509. 
Tsai, W.-B., Aiba, I., Lee, S.-y., Feun, L., Savaraj, N., Kuo, M.T., (2009) Resistance to arginine deiminase treatment in melanoma cells is associated with induced argininosuccinate synthetase expression involving c-Myc/HIF-1 alpha/Sp4. Mol. Cancer Ther. 8, 3223-3233.

Tsai, W.B., Long, Y., Park, J.R., Chang, J.T., Liu, H., Rodriguez-Canales, J., Savaraj, N., Feun, L.G., Davies, M.A., Wistuba, I.I., Kuo, M.T., (2016) Gas6/Axl is the sensor of arginine-auxotrophic response in targeted chemotherapy with arginine-depleting agents. Oncogene 35, 1632-1642.

Tsikas, D., Beckmann, B., Gutzki, F.-M., Jordan, J., (2011) Simultaneous gas chromatography-tandem mass spectrometry quantification of symmetric and asymmetric dimethylarginine in human urine. Anal. Biochem. 413, 60-62.

Tsikas, D., Schubert, B., Gutzki, F.M., Sandmann, J., Frolich, J.C., (2003) Quantitative determination of circulating and urinary asymmetric dimethylarginine (ADMA) in humans by gas chromatography-tandem mass spectrometry as methyl ester tri(N-pentafluoropropionyl) derivative. J. Chromatogr. B 798, 87-99.

Tswett, M., (1906a) Adsorptionsanalyse und chromatographische Methode. Anwendung auf die Chemie des Chlorophylls. Ber. Deut. Bot. Ges. 24, 384-393.

Tswett, M., (1906b) Physikalisch-chemische Studien über das Chlorophyll. Die Adsorptionen. Ber. Deut. Bot. Ges. 24, 316-323.

Ulehla, J., (1960) Plynova chromatografie produktu pyrolyzy aminokyselin. (Gas chromatography of the products of pyrolysis of amino acids). Zivocisna Vyroba 5, 567-574.

van de Poll, M.C.G., Siroen, M.P.C., van Leeuwen, P.A.M., Soeters, P.B., Melis, G.C., Boelens, P.G., Deutz, N.E.P., Dejong, C.H.C., (2007) Interorgan amino acid exchange in humans: consequences for arginine and citrulline metabolism. Am J Clin Nutr 85, 167-172.

van der Sluis, I.M., Vrooman, L.M., Pieters, R., Baruchel, A., Escherich, G., Goulden, N., Mondelaers, V., de Toledo, J.S., Rizzari, C., Silverman, L.B., Whitlock, J.A., (2016) Consensus expert recommendations for identification and management of asparaginase hypersensitivity and silent inactivation. Haematologica 101, 279-285.

Van Eeckhaut, A., Lanckmans, K., Sarre, S., Smolders, I., Michotte, Y., (2009) Validation of bioanalytical LCMS/MS assays: Evaluation of matrix effects. J. Chromatogr. B 877, 2198-2207.

van Vliet, D., Derks, T.G.J., van Rijn, M., de Groot, M.J., MacDonald, A., Heiner-Fokkema, M.R., van Spronsen, F.J., (2014) Single amino acid supplementation in aminoacidopathies: A systematic review. Orphanet J. of Rare Dis. 9, 14. DOI: 10.1186/1750-1172-9-7

Vauquelin, L.N., Robiquet, P.J., (1806) Découverte d'un nouvelle principe végétal dans le suc des asperges. Ann. Chim., 88-93.

Verheggen, T., Mikkers, F.E.P., Everaerts, F.M., (1977) Isotachophoresis in narrow-bore tubes influence of diameter of separation compartment. J. Chromatogr. 132, 205-215.

Vishinkin, R., Haick, H., (2015) Nanoscale sensor technologies for disease detection via volatolomics. Small 11, 6142-6164.

Vlaardingerbroek, H., Vermeulen, M.J., Rook, D., van den Akker, C.H.P., Dorst, K., Wattimena, J.L., Vermes, A., Schierbeek, H., van Goudoever, J.B., (2013) Safety and efficacy of early parenteral lipid and highdose amino acid administration to very low birth weight infants. J. Pediatr. 163, 638-644.

Voellmin, J., Kriemler, P., Omura, I., Seibl, J., Simon, W., (1966) Structural elucidation with a thermal fragmentation gas chromatography mass spectrometry combination. Microchem. J. 11, 73-86.

Vynnytska-Myronovska, B., Bobak, Y., Garbe, Y., Dittfeld, C., Stasyk, O., Kunz-Schughart, L.A., (2012) Single amino acid arginine starvation efficiently sensitizes cancer cells to canavanine treatment and irradiation. Int. J. Cancer 130, 2164-2175.

Vynnytska-Myronovska, B., Kurlishchuk, Y., Bobak, Y., Dittfeld, C., Kunz-Schughart, L.A., Stasyk, O., (2013) Three-dimensional environment renders cancer cells profoundly less susceptible to a single amino acid starvation. Amino Acids 45, 1221-1230.

Vynnytska-Myronovska, B.O., Kurlishchuk, Y., Chen, O., Bobak, Y., Dittfeld, C., Huether, M., Kunz-Schughart L.A., Stasyk, O.V., (2016) Arginine starvation in colorectal carcinoma cells: Sensing, impact on translation control and cell cycle distribution. Exp. Cell Res. 341, 67-74.

Wang, L., Wang, J.-h., Wu-Xiao, Z.-j., Xia, Z.-J., Huang, H.-q., Lu, Y., (2015) Lymphopenia during routine followup may predict relapse in patients with extranodal NK/T cell lymphoma. Tumor Biol. 36, 1747-1753.

Wang, Y.-Q., Ye, D.-Q., Zhu, B.-Q., Wu, G.-F., Duan, C.-Q., (2014) Rapid HPLC analysis of amino acids and biogenic amines in wines during fermentation and evaluation of matrix effect. Food Chem. 163, 615.

Way, J.T., (1850) On the Power of Soils to absorb Manure. J. R. Agric. Soc. Engl.

Way, J.T., (1852) Der doppeltphosphorsaure Kalk, seine Bestandteile, Bereitung und Anwendung als Düngungsmittel: Aus dem Englischen, 1st ed. Ueberreuter.

Wellner, A., Huettl, C., Henle, T., (2009) Influence of heat treatment on the formation of amadori compounds in carrots. Czech J. Food Sci. 27, S143-S145.

Wiklund, P.K., Pekkala, S., Autio, R., Munukka, E., Xu, L., Saltevo, J., Cheng, S., Kujala, U.M., Alen, M., Cheng, S., (2014) Serum metabolic profiles in overweight and obese women with and without metabolic syndrome. Diabetol. Metab. Syndr. 6. DOI: 10.1186/1758-5996-6-40

Williams, A.P., (1986) General problems associated with the analysis of amino acids by automated ion-exchange chromatography. J. Chromatogr. A 373, 175-190.

Winter, L.N., Albro, P.W., (1964) Differentiation of amino acids by gas liquid chromatography of their pyrolysis products. J. Gas Chromatogr. 2, 1-6.

Wu, G.Y., (2009) Amino acids: metabolism, functions, and nutrition. Amino Acids 37, 1-17.

Wu, G.Y., Morris, S.M., (1998) Arginine metabolism: nitric oxide and beyond. Biochem. J. 336, 1-17. 
Wu, R., Liu, Q., Zhang, P., Liang, D., (2016) Tandem amino acid repeats in the green anole (Anolis carolinensis) and other squamates may have a role in increasing genetic variability. BMC Genomics 17 , DOI: 10.1186/s12864-016-2430-y .

Wuertz, P., Soininen, P., Kangas, A.J., Ronnemaa, T., Lehtimaki, T., Kahonen, M., Viikari, J.S., Raitakari, O.T., Ala-Korpela, M., (2013) Branched-chain and aromatic amino acids are predictors of insulin resistance in young adults. Diabetes Care 36, 648-655.

Xing, Y.P., Li, X.Y., Guo, X.J., Cui, Y., (2016) Simultaneous determination of 18 D-amino acids in rat plasma by an ultrahigh-performance liquid chromatography-tandem mass spectrometry method: application to explore the potential relationship between Alzheimer's disease and D-amino acid level alterations. Anal. Bioanal. Chem. 408, 141-150.

Yamakado, M., Nagao, K., Imaizumi, A., Tani, M., Toda, A., Tanaka, T., Jinzu, H., Miyano, H., Yamamoto, H., Daimon, T., Horimoto, K., Ishizaka, Y., (2015) Plasma free amino acid profiles predict four-year risk of developing diabetes, metabolic syndrome, dyslipidemia, and hypertension in Japanese population. Sci. Rep. 5. DOI:10.1038/srep11918

Yamashita, M., Fenn, J.B., (1984) Electrospray ion source. Another variation on the free-jet theme. J. Phys. Chem. 88, 4451-4459.

Yatabe, J., Yatabe, M.S., Ishibashi, K., Nozawa, Y., Sanada, H., (2013) Early detection of colon cancer by amino acid profiling using Aminolndex technology: a case report. Diagn. Pathol. 8, DOI: 10.1186/17461596-8-203.

Yaylayan, V.A., Locas, C.P., Wnorowski, A., O'Brien, J., (2005) Mechanistic pathways of formation of acrylamide from different amino acids. Chemistry and Safety of Acrylamide in Food 561, 191-203.

Yemm, E.W., Cocking, E.C., (1955) The determination of amino acids with ninhydrin. Analyst 80, 209-213.

Yoo, M.Y., Paeng, J.C., Cheon, G.J., Lee, D.S., Chung, J.-K., Kim, E.E., Kang, K.W., (2015) Prognostic value of metabolic tumor volume on (11)C-methionine PET in predicting progression-free survival in highgrade glioma. Nucl. Med. Mol. Imaging 49, 291-297.

Yoon, H.-R., (2013) Determination of plasma dibasic amino acids following trimethylsilyl-trifluoroacyl derivatization using gas chromatography-mass spectrometry. Arch. Pharm. Res. 36, 366-373.

Zahradnickova, H., Husek, P., Simek, P., Hartvich, P., Marsalek, B., Holoubek, I., (2007) Determination of D- and L-amino acids produced by cyanobacteria using gas chromatography on Chirasil-Val after derivatization with pentafluoropropyl chloroformate. Anal. Bioanal. Chem. 388, 1815-1822.

Zhang, C.H., Xu, K.M., Dave, U.P., Wang, Y., Matsumoto, I., (2000) Inborn errors of metabolism discovered in Asian department of pediatrics and mental retardation research center. J. Chromatogr. B 746, 4149.

Zhang, X., Wang, H., Ma, Z., Wu, B., (2014) Effects of pharmaceutical PEGylation on drug metabolism and its clinical concerns. Expert Opin. Drug Metab. Toxicol. 10, 1691-1702.

Zhao, Q., Cao, Y., Wang, Y., Hu, C., Hu, A., Ruan, L., Bo, Q., Liu, Q., Chen, W., Tao, F., Ren, M., Ge, Y., Chen, A., Li, L., (2014) Plasma and tissue free amino acid profiles and their concentration correlation in patients with lung cancer. Asia Pac. J. Clin. Nutr. 23, 429-436.

Zhou, G., Pang, H., Tang, Y., Yao, X., Mo, X., Zhu, S., Guo, S., Qian, D., Qian, Y., Su, S., Zhang, L., Jin, C., Qin, Y., Duan, J.-a., (2013) Hydrophilic interaction ultra-performance liquid chromatography coupled with triple-quadrupole tandem mass spectrometry for highly rapid and sensitive analysis of underivatized amino acids in functional foods. Amino Acids 44, 1293-1305.

Zhou, G., Wang, M., Li, Y., Peng, Y., Li, X., (2015) Rapid and sensitive analysis of 27 underivatized free amino acids, dipeptides, and tripeptides in fruits of Siraitia grosvenorii Swingle using HILIC-UHPLCQTRAP Itextregistered /MS2 combined with chemometrics methods. Amino Acids 47, 1589-1603.

Zimmermann, W., (1930) Über den Nachweis kleiner Mengen Glykokoll. H-S Z. Physiol. Chem. 189, 4-6.

Zuman, P., (2004) Reactions of orthophthalaldehyde with nucleophiles. Chem. Rev. 104, 3217-3238.

Zurawicz, E., Kaluzna-Czaplinska, J., (2015) Analysis of amino acids in autism spectrum disorders. Trends Anal. Chem. 73, 91-118. 